\title{
Reactive RED 195 dye removal using chitosan coacervated particles as bio-sorbent: Analysis of kinetics, equilibrium and adsorption mechanisms
}

\author{
John Pérez-Calderón ${ }^{\mathrm{a}}$, María V. Santos ${ }^{\mathrm{a}, \mathrm{b}}$, Noemí Zaritzky ${ }^{\mathrm{a}, \mathrm{b}, *}$ \\ a Centro de Investigación y Desarrollo en Criotecnología de Alimentos CIDCA (Facultad de Cs. Exactas UNLP-CONICET-CIC), La Plata, Calle 47 y 116, CP 1900, \\ Argentina \\ b Depto. de Ingeniería Química, Facultad de Ingeniería, Universidad Nacional de La Plata, La Plata, Calle 1 y 47, CP 1900, Argentina
}

\section{A R T I C L E I N F O}

\section{Keywords:}

Chitosan coacervated particles

Reactive Red

195

Azo dye removal

Adsorption

Thermodynamic analysis

\begin{abstract}
A B S T R A C T
Chitosan particles (CP) prepared by coacervation technique were used as bio-sorbent material to remove the azo RR-195 dye; removal percentage (\%RM) and adsorption capacity $(Q)$ in batch adsorption experiments under different conditions of bio-sorbent doses, agitation speed and $\mathrm{pH}$ medium were determined; the maximum $\mathrm{pH}$ of dye removal was 4. Different adsorption equilibrium isotherms were tested and Redlich-Peterson was the model that best fitted experimental results. From the adsorption thermodynamic parameters, it was concluded that the adsorption process of RR-195 onto CP is spontaneous, favorable $(\Delta G<0)$, endothermic $(\Delta H>0)$ and the dye molecules show affinity for the bio-sorbent $(\Delta S>0)$. The maximum monolayer adsorption capacity $\left(Q_{m}\right)$ of $\mathrm{CP}$ was $82.1 \mathrm{mg} \cdot \mathrm{g}^{-1}$ at $\mathrm{pH}=4$ and $318 \mathrm{~K}$; therefore coacervated chitosan particles are among the top three adsorbent agents for this dye. The $\% R M$ was $84.2 \%$ in $10 \mathrm{~h}$ when the initial concentration of the dye was 300 mg.L ${ }^{-1}$. The mixed surface reaction and diffusion-controlled kinetic model (MSR-DCK), fitted satisfactorily experimental results, by considering simultaneous mechanisms of diffusion and adsorption process in the active sites. Fourier transform infrared spectroscopy (FTIR) with attenuated total reflection (ATR), scanning electron microscope-energy dispersion spectrometry X-ray (SEM-EDS) and Zeta potential analysis revealed that the interaction between dye molecules and the bio-sorbent are of an electrostatic nature. Desorption/regeneration experiments indicated that CP can be used in adsorptions/desorption cycles for the removal of wastewater containing RR-195. The information presented in this work demonstrates that CP can be a potent eco-friendly bio-adsorbent for the remediation of industrial wastewater.
\end{abstract}

\section{Introduction}

The contamination of water due to the presence of synthetic dyes is a serious environmental problem since the production of these compounds is estimated at 1.6 million tons and approximately $10-15 \%$ of this amount is discarded into water streams [1]. Several industries such as paper, textile, graphic, leather and plastic generate wastewater with the presence of these pollutants [2]. This wastewater is characterized by having a high organic matter content that affects the water quality and increases the chemical and biological oxygen demand [3,4]. The chemical structure of the dyes is important since they are difficult to be biodegraded [4,5] and can break down to form hazardous chemical substances; for example, azo dyes can form aromatic amines (including benzidine) which are human carcinogenic [6].

In aquatic environments, the presence of dyes reduces the penetration of light and oxygen, affecting the normal photosynthetic activity which in turn deteriorates the aquatic biota [7]. Moreover, these toxic compounds affect the human health; several pathologies such as cancer, jaundice, tumors, skin irritation, allergies, heart effects and mutation arise due to exposure to contaminated wastewater [8,9]. The chemical structure of the dyes allows to classify them as anionic (direct, acid and reactive dyes); cationic (basic dyes); and non-ionic (disperse dyes) [4]. The azo dyes are one of the most important synthetic dyes and they are characterized by having an azo group $(-\mathrm{N}=\mathrm{N}-$ ) as chromophore, in addition to sulfonate groups $\left(-\mathrm{SO}_{3}{ }^{-}\right)$, giving the molecule its anionic nature. In the present work the removal of the azo dye Reactive Red 195 (RR-195) was analyzed. It is a reactive mono azo dye (description of is chemical structure is provided as Supplementary material, S1). Reactive dyes represent approximately over $12 \%$ of the worldwide production [10] and are extensively used in textile and printing industries [11] for dyeing of cellulose, wool and cotton fiber [12]. Reactive dyes form covalent bonds with the fibers that are to be colored;

\footnotetext{
* Corresponding author at: CIDCA- Fac. Cs. Exactas UNLP, Calle 47 y 116, La Plata, 1900, Argentina.

E-mail address: zaritzky@ing.unlp.edu.ar (N. Zaritzky).
} 
the dye molecule contains specific functional groups that can undergo substitution or addition reactions with $-\mathrm{OH}$ (hydroxyl), $-\mathrm{SH}$ (thiol), and $-\mathrm{NH}_{2}$ (amino) groups of textile fibers [13]. About $20-40 \%$ of the reactive dyes remain in the waste waters as recalcitrant compounds producing high alkalinity, high concentration of organic materials and strong color in comparison with other dyes [14].

Advanced oxidation technology, coagulation/flocculation, separation by membranes, photo-degradation and biological treatments are the most common techniques to remove dyes in industrial wastewater $[15,16]$. These techniques have disadvantages such as: (i) incomplete removal of dyes generating contaminated influents, (ii) high operating costs due to energy requirements, (iii) generation of toxic products such as sludge and new hazardous chemical compounds [17].

Frequently adsorption has been used as the most effective method to treat this type of wastewater [4]. There are mainly four kinds of interactions that occur in the adsorption process: pore adsorption, electrostatic attraction, ion-exchange, and chemical association between the surface of the adsorbent and the dye molecules [18]. Attempts to describe the mechanisms that are involved during adsorption processes, include different techniques such as FTIR spectra, zeta potential, kinetic and thermodynamic studies, among others [18,19].

Many researches characterized activated carbon as one of the best adsorbents but the production of this material is expensive and polluting. Other low-cost adsorbents such as clays are used for the removal of dyes in water, but these have a low adsorption performance $[7,15,20]$.

Several scientific works reported the use of different RR-195 adsorbents, such as $\mathrm{TiO}_{2}$ nanoparticles [21], wheat bran [22], dehydrated beet pulp carbon [23], modified Palygorskite [24], rice husk [25], Pinus sylvestris L. biomass [26], modified switchgrass biochar [17] and cotton woven fabric in a nonionic surfactant Triton X-100 [27].

The use of bio-sorbents is a recent strategy; these materials are biodegradable and can be obtained from agro-industrial wastes [4]. Among the bio-sorbents, chitosan can be selected because it is a biodegradable and non-toxic biopolymer that is prepared by deacetylation of the acetamide groups of chitin (second abundant polymer in nature after cellulose) [28]. This compound is an important renewable resource, which is obtained from the shells of crustaceans waste [29]. Chitosan is a copolymer polysaccharide of $\beta$-(1-4)-D-glucosamine (deacetylated units) and $\mathrm{N}$-acetyl-D-glucosamine (acetylated unit); its main difference with chitin is the presence of free amino groups $\left(-\mathrm{NH}_{2}\right)$, which confer a cationic nature to this polyelectrolyte in acid medium with numerous applications for wastewater treatment $[9,19,30]$. The use of chitosan in different forms (flakes, hydrogels, beads or fibers) has been reported in literature as effective adsorbent materials [31], establishing as an attractive non-conventional alternative due to its chemical stability and selectivity towards various types of dyes such as the azo dye Reactive Red 195 (RR-195).

Wen et al. [32] used chitosan flakes for the adsorption of RR-195 demonstrating that it can be removed efficiently, but several investigations indicate that the flakes have low adsorption capacities for reactive azo dyes compared to chitosan beads $[19,33]$.

The novelty of the present work is the application of chitosan alkaline coacervated particles (CP) for the removal of RR-195; this system has not been thoroughly studied in literature and there is limited information concerning the kinetics, equilibrium isotherms, thermodynamic parameters as well as the nature of the interaction mechanisms between the dye and these particles.

The objectives of the present study were: a) to synthetize chitosan particles by alkaline coacervation (CP) in order to remove azo RR-195 dye; $\mathrm{b})$ to determine the removal percentage (\%RM) and adsorption capacity $(Q)$ in batch adsorption experiments under different experimental conditions (bio-sorbent doses, agitation speed and solution $\mathrm{pH}$ ) and to compare results with reported literature data; c) to obtain the adsorption isotherms and to select the model (Langmuir, Freundlich, Temkin, Redlich-Peterson (R-P) or Dubinin-Radushkevich (D-R)) that best fits experimental results using regression analysis and statistical tests; d) to calculate the thermodynamic parameters: enthalpy $(\Delta H)$, Gibbs free energy $(\Delta G)$ and entropy $(\Delta S)$; e) to test different equations for describing adsorption kinetics (Pseudo first order (Ps1), Pseudo second order (Ps2), Elovich, Intraparticle diffusion, and the mixed surface reaction and diffusion-controlled kinetic model (MSR-DCK)); f) to analyze the adsorption mechanisms; g) to study the desorption process and regeneration of the bio-sorbent by applying adsorption/desorption cycles; h) to characterize the interactions between the bio-sorbent material and the RR-195 dye, using different techniques: zeta potential; Fourier transform infrared spectroscopy (FTIR) with attenuated total reflection (ATR); Scanning electron microscopy (SEM) with energy dispersive X-ray analysis (EDS).

\section{Materials and methods}

\subsection{Materials}

Chitosan flakes from crab shells were purchased from Sigma-Aldrich (St. Louis, MO, USA) with a deacetylation degree of $75.3 \pm 1.1 \%$ determined by FTIR method [34]; the molecular weight of $2.83 \times 10^{5}$ g. $\mathrm{mol}^{-1}$ was obtained by viscometric method using an Ostwald capillary viscometer. The dye Reactive Red 195 (RR-195) was provided by a national dye industry Chromeco S.A (Gral. Pacheco, Argentina).The chemical structure of the dye is shown as supplementary material (S1).

\subsection{Preparation of the bio-sorbent}

The chitosan particles (CP) were prepared using the coacervation/ precipitation technique in alkali medium. A solution of chitosan at a concentration of $2.5 \%\left(\mathrm{w} . \mathrm{v}^{-1}\right)$ was prepared by solubilizing chitosan flakes in $1.5 \%\left(\mathrm{v} . \mathrm{v}^{-1}\right)$ acetic acid (Anedra, Buenos Aires, Argentina) at $25^{\circ} \mathrm{C}$ under stirring conditions for $12 \mathrm{~h}$. The $\mathrm{CP}$ were made by dripping chitosan solution through a $4 \mathrm{~mm}$ inner diameter orifice onto a $1 \mathrm{M}$ sodium hydroxide solution, using a Minipuls 3 peristaltic pump (Gilson, Villiers le Bel, France) at 45 rev. $\mathrm{min}^{-1}$. The hydrogel particles formed were washed with distilled water until the excess alkali was released, then dried at $55^{\circ} \mathrm{C}$ in a forced convection oven for $24 \mathrm{~h}$. The dried CP were kept in a hermetic container free of moisture until use.

\subsection{Characterization of the bio-sorbent}

The morphology of the bio-sorbent was observed by scanning electron microscope (SEM) micrographs. The NeoScope Benchtop JEOL JCM-6000 microscope (JEOL, U.S.A) was used, equipped with energy dispersion spectrometry X-ray (EDS) unit JEOL WX-36210DPP.

Fourier transform infrared spectroscopy (FTIR) with attenuated total reflection (ATR) was applied. Spectra were recorded in \%Transmittance mode with 34 scans and $4 \mathrm{~cm}^{-1}$ spectral resolutions. The FTIR-ATR spectra were recorded between $4000-500 \mathrm{~cm}^{-1}$ using on a Thermo Nicolet iS10 spectrometer (Thermo Scientific, MA, U.S.A). The ATR accessory contained diamond crystal with $\mathrm{ZnSe}$ and Ge lens, the nominal angle of incidence is $42^{\circ}$.

A nanoparticle analyzer SZ-100-Z (Horiba Instrunents Inc., Kyoto, Japan) provided with a laser diode model JUNO 10G-HO (Showa Optronics Co., Ltd., Yokohama, Japan) operating at $532 \mathrm{~nm}$ was used to determine zeta potential (ZP) by electrophoretic mobility of the suspension solution containing CP using an electrode cell (carbon, $6 \mathrm{~mm}$ ). $\mathrm{ZP}$ was reported as the average of five determinations per sample.

Microstructural properties such as pore size distribution, specific surface and pore volume were determined by $\mathrm{N}_{2}$ desorption method using an Accelerated Surface Area and Porosimetry System Micromeritics Model 2020 (Micromeritics, GE, and U.S.A). The mean diameter of the bio-sorbent was determined by analyzing at least fifty micrographs of CP using a MZ $10 \mathrm{~F}$ stereomicroscope with DFC490 camera (Leica Microscopy Systems Ltd, Germany). CP diameters were 
measured using the Image $\mathrm{J}$ software [35].

\subsection{Study of the performance of the bio-adsorbent}

\subsubsection{Batch adsorption experiments}

The adsorption experiments were carried out evaluating the percentage of dye removal (\%RM; Eq. 1) under different test conditions (adsorbent dose, $\mathrm{pH}$ variation and stirring speed).

$\% R M=\frac{C_{0}-C_{f}}{C_{0}} \times 100$

where $C_{o}$ is the initial concentration of the solution (mg.L ${ }^{1}{ }^{1}$ ) and $C_{f}$ the final concentration. The adsorption capacity $(Q)$ is defined as:

$Q=\frac{\left(C_{0}-C\right)}{W} \times V$

where $C$ is the concentration at a given time $t, V$ is the volume of the solution (L) and $W$ is the dose of $\mathrm{CP}(\mathrm{g})$. The adsorption capacity at equilibrium conditions $\left(Q_{e}\right)$ can be defined in Eq. 2, when $C$ is replaced by $C_{e}$ (equilibrium concentration).

Batch experiments were conducted using an initial RR-195 concentration of $C_{O}=100 \mathrm{mg} . \mathrm{L}^{-1}$ and $V=0.05 \mathrm{~L}$; the $\mathrm{pH}$ of the medium was adjusted with sodium hydroxide and hydrochloric acid $0.1 \mathrm{M}$; the shaker speed was kept constant during the tests using a temperature control $(\mathrm{T}=298 \mathrm{~K})$. The final dye concentration was determined by UV-vis spectrophotometry using Hach DR 2800 spectrophotometer (Loveland, Colorado, USA) at a wavelength of $538 \mathrm{~nm}$.

The effect of mass of bio-sorbent on the $\% R M$ and $Q$ was analyzed varying the doses of $\mathrm{CP}\left(2.0\right.$ to $\left.5.0 \mathrm{~g}_{\mathrm{CP}} \cdot \mathrm{L}^{-1}\right)$; the effect of agitation speed was studied in the range 50 to $250 \mathrm{rev} \cdot \mathrm{min}^{-1}$. The influence of $\mathrm{pH}$ on the \%RM and $\mathrm{ZP}$ was assessed varying the $\mathrm{pH}$ from 2.5 to 13 . From the assays, the experimental conditions (adsorbent dosage, $\mathrm{pH}$ variation and agitation speed) that achieved the highest $\% R M$ were selected to perform the isotherms and kinetics studies.

\subsubsection{Equilibrium adsorption isotherms and thermodynamic parameters}

Adsorption isotherms were obtained from experiments where CP dosage was maintained constant, and different initial concentrations of RR-195 were tested (40-500 mg. $\mathrm{L}^{-1}$ ); the volume of the adsorbate was $0.050 \mathrm{~L}$.

The adsorption isotherm describes the relation between the quantity adsorbed and the concentration of the dye in the bulk phase under equilibrium conditions at constant temperature. Several equations have been used to fit the experimental data of RR-195 adsorption using CP.

The tested models were Langmuir, Freundlich, Temkin, DubininRadushkevich (D-R) and Redlich-Peterson (R-P). The equations used to analyze the isotherms are described in Table 1 (Eqs (3)-(7)). Non-linear regressions were applied to calculate the parameters for each model. The study of the adsorption isotherms was carried out at different temperatures $(298,308$ and $318 \mathrm{~K}$ ) in order to obtain the thermodynamic parameters.

Table 1

Equations used for the non-linear regressions of the adsorption isotherm models.

\begin{tabular}{ll}
\hline Model & Equation \\
\hline Langmuir & $Q_{e}=\frac{Q_{m} \cdot K_{L} \cdot C_{e}}{1+K_{L} C_{e}}(3)$ \\
Freundlich & $Q_{e}=K_{F} \cdot C_{e}^{1 / n}(4)$ \\
Temkin & $Q_{e}=B_{t} \cdot \ln \left(A_{t} \cdot C_{e}\right)(5)$ \\
Redlich-Peterson (R-P) & $Q_{e}=\frac{K_{R P} \cdot C_{e}}{1+\left(\alpha \cdot C_{e}^{\beta}\right)}(6)$ \\
Dubinin-Radushkevich (D-R) & $Q_{e}=Q_{D R \cdot \exp ^{-\varepsilon^{2}} \cdot K_{D R}}(7)$
\end{tabular}

Table 2

Equations used for the non-linear regressions of the adsorption kinetic models.

\begin{tabular}{ll}
\hline Model & Equation \\
\hline Pseudo first order (Ps1) & $Q=\left(1-\exp ^{-k_{1} \cdot t}\right)(9)$ \\
Pseudo second order (Ps2) & $Q=\frac{k_{2} \cdot Q^{2} \cdot t}{1+k_{2} \cdot Q_{e} \cdot t}(10)$ \\
Elovich & $Q=\frac{1}{\beta} \ln (1+\alpha \cdot \beta \cdot t)(11)$ \\
Intraparticle diffusion & $Q=k_{i} t^{0.5}+c(12)$ \\
MSR-DCK & $\left.Q=Q_{e} \frac{\exp \left(a . t+b . t^{0.5}\right)}{\left(u_{e q} \cdot \exp \left(a . t+b . t^{0.5}\right)\right.}-1\right)$ \\
&
\end{tabular}

\subsubsection{Adsorption kinetics}

The adsorption kinetic experiments were carried out by mixing $\mathrm{CP}$ $(0.2 \mathrm{~g})$ with $0.050 \mathrm{~L}$ of RR-195 solution varying the initial concentration $\left(100,200\right.$ and $\left.300 \mathrm{mg} \mathrm{L}^{-1}\right)$. The dye concentration was determined at different tested times. The adsorption capacity at a given time $(Q)$ was defined in Eq. 2

The swelling degree $(\% S D)$ and the change in the mean diameter of the $\mathrm{CP}$ during the adsorption process were determined at specific times. The $\% S D$ was determined using Eq.3:

$\% S D=\left(\frac{W_{t}-W_{o}}{W_{o}}\right) \times 100$

where $w_{t}$ is the mass of the bio-sorbent material after adsorption and $w_{o}$ is the initial mass of this material. Changes in the mean diameter of the coacervated particles were calculated as indicated in section 2.3.

The kinetic models tested were: Pseudo first order (Ps1), Pseudo second order (Ps2), Elovich, Intraparticle diffusion and the Mixed surface reaction and diffusion-controlled kinetic model (MSR-DCK); the corresponding equations are shown in Table 2 (Eqs (9)-(13)).

\subsubsection{Desorption and Regeneration of the bio-sorbent}

After the first batch of adsorption experiments with an initial dye concentration of $C_{o}=300 \mathrm{mg} . \mathrm{L}^{-1}$ coacervated particles were used to evaluate their desorption capacity $\left(Q_{D}\right) . Q_{D}$ of the CP was calculated as follows:

$Q_{D}=\frac{\left(C_{t}-C_{0}\right)}{W} \times V$

where $C_{t}$ corresponds to the concentration of dye at a time $t, C_{o}$ is the initial concentration of dye in the liquid during desorption $\left(C_{o}=0 \mathrm{mg} \cdot \mathrm{L}^{-1}\right), W$ is the mass of absorbent used and $V$ the test volume $(0.050 \mathrm{~L})$

Desorption process was carried out placing the CP containing the adsorbed dye in pure Milli $\mathrm{Q}$ water $(0.050 \mathrm{~L})$ at $\mathrm{pH}=12$. A second adsorption cycle was carried out with the regenerated $\mathrm{CP}$. The regenerated bio-adsorbent material was dried in a forced convention oven at $55{ }^{\circ} \mathrm{C}$ until constant weight. The regenerated $\mathrm{CP}$ were submitted to a second adsorption cycle with a RR-195 concentration of $C_{o}=300 \mathrm{mg} . \mathrm{L}^{-1}(V=0.050 \mathrm{~L})$.

\subsection{Statistical analysis}

The software Origin Pro 8 (Origin Lab Corporation, Northampton, Ma., U.S.A.) was used to obtain linear and non -linear regressions, to determine the corresponding parameters and to perform statistical analyses of the sorption equilibrium isotherms, kinetic equations and thermodynamic parameters. After fitting the proposed models to the experimental data, the goodness of fit was evaluated taking into account the determination coefficient $\left(R^{2}\right)$, average absolute percentage error $(\% e)$ and chi-square distribution error $\left(\chi^{2}\right)$; \%e and $\chi^{2}$ were determined with the Eqs. 5 and 6 respectively, where $y_{e}$ is the experimental value and $y_{p}$ is the value predicted by the model. 
a.

C.
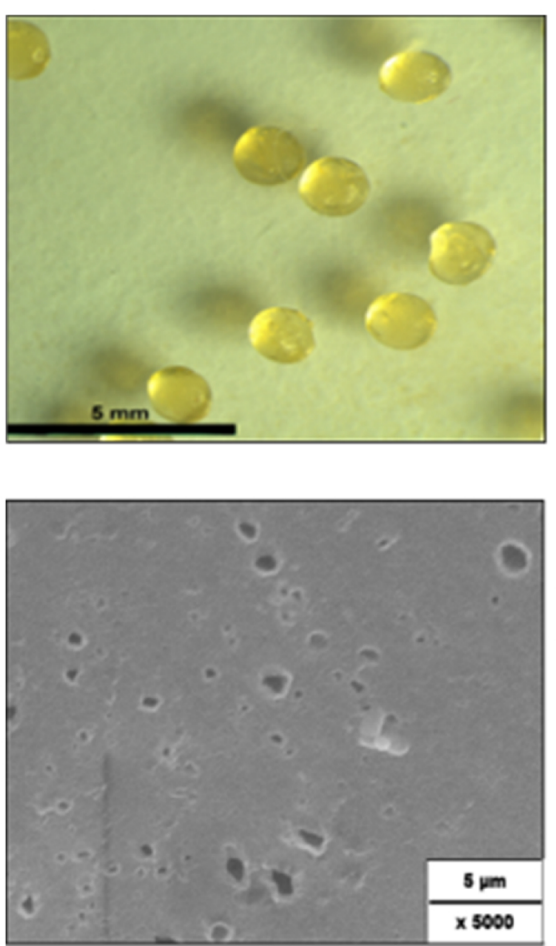

b.

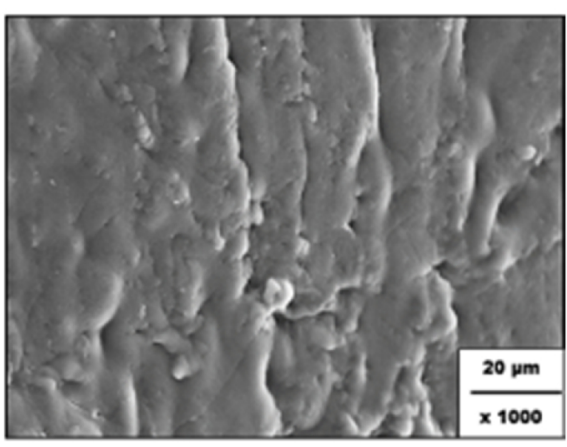

d.

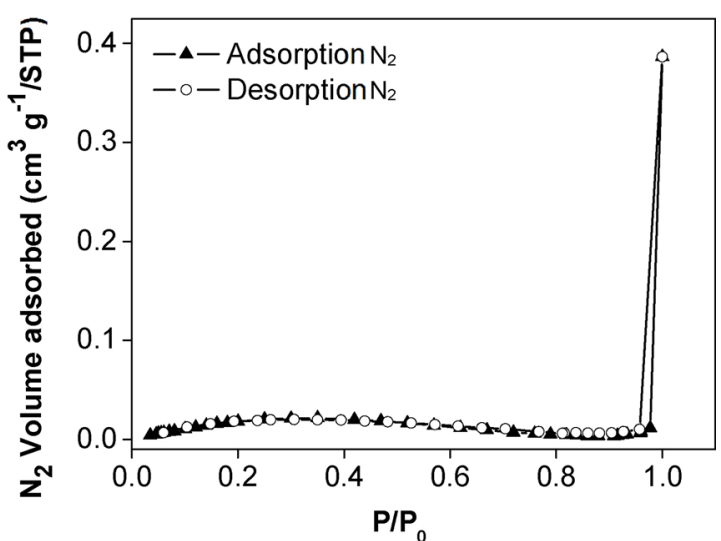

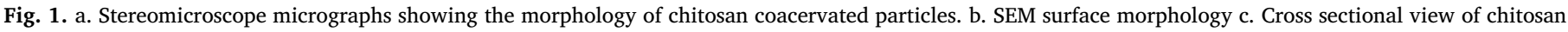
coacervated particles. d. $\mathrm{N}_{2}$ adsorption-desorption isotherms for chitosan coacervated particles.

$\% e=\frac{\sum\left|\left(y_{e}-y_{p}\right) / y_{e}\right|}{n} \times 100$

$\chi^{2}=\sum \frac{\left(y_{e}-y_{p}\right)^{2}}{y_{p}}$

The analysis of variance (ANOVA) was conducted to assess significant differences between the samples; means were compared by a Fisher LSD test using a 95\% confidence level (significant difference, $\mathrm{P} \leq 0.05$ ). To determine which model best fits the experimental data the predicted values form the model versus the experimental values were plotted and the $\%$ of deviation $(\% D P)$ from the linear equation $\mathrm{y}=\mathrm{x}$ that contains $95 \%$ of the experimental values was calculated.

\section{Results and discussion}

\subsection{Morphology and microstructural properties of bio-sorbent}

Fig. 1a shows the micrograph of coacervated particles (CP) with a mean diameter of $1.87 \mathrm{~mm}$ (Standard deviation, $S D=0.28$ ). The SEM micrograph of the CP surface before adsorption is shown in Fig. 1b and the cross-section of CP is observed in Fig. 1c. CP shows a porous appearance with smoothed folds. The microstructural properties were determined by the $\mathrm{N}_{2}$ adsorption/desorption method. The measured average pore diameter was $20.07 \mathrm{~nm}$, then $\mathrm{CP}$ was classified as mesoporous material, because it contains pores with diameters ranging between 2 and $50 \mathrm{~nm}$, according to IUPAC nomenclature [36]. The specific surface area of the pores according to the BET method was $0.120 \mathrm{~m}^{2} \cdot \mathrm{g}^{-1}$; similarly Azlan et al., [37] reported a value of $0.96 \mathrm{~m}^{2} \cdot \mathrm{g}^{-1}$ for coacervated chitosan beads. The $\mathrm{N}_{2}$ inclusion and exclusion isothermal curves (Fig. 1d) showed almost no hysteresis indicating a lack of pore connectivity within the bio-sorbent [38], which implies that the pore-adsorption contribution is low.

\subsection{Experimental conditions selected for the adsorption of RR 195}

The experimental results of $\% R M$ and $Q$ were plotted against the dose of bio-sorbent in order to select the experimental conditions for the equilibrium isotherms and kinetic studies. The removal of dye increased with the increase of bio-sorbent concentration, however considering that the goal is to reach a high level of removal without using large amounts of adsorbents, the adsorption capacity should be taken into account. From Fig.2a, a dose of $4.0 \mathrm{~g}_{\mathrm{CP} . \mathrm{L}^{-1}}$ was chosen for the subsequent tests, since with this concentration a value of $\% R M=85.6$ was achieved, not observing significant changes in $Q$ values, above this dose.

Fig. $2 \mathrm{~b}$ shows that an increase in the stirring rate produced higher $\%$ $R M$ values, because it favors the distribution of the molecules of the dye surrounding the adsorbent [39]. A speed of $200 \mathrm{rev} \cdot \mathrm{min}^{-1}$ was selected for the different experiments.

Fig. 2c shows the effect of $\mathrm{pH}$ on the $\% R M$ of $\mathrm{RR}-195$ and $\mathrm{Z}$ potential before and after adsorption. The removal of this dye from wastewater is dependent on the $\mathrm{pH}$ of the solution since it affects the surface charge of the bio-sorbent, and also affects the degree of ionization of the azo-dye. $\mathrm{Z}$ Potential measurements were performed in order to determine the isoelectric point $\left(\mathrm{pH}_{\mathrm{IEP}}\right)$ of the bio-sorbent. The shift of the isoelectric point estimated through ZP measurements is an indicator of possible changes in the chemical structure of the adsorbent.

According to Fig. 2c, the removal of the dye (\%RM) was maximum at $\mathrm{pH}=4$ since at this $\mathrm{pH}$ there is a maximum number of protonated amino groups in $\mathrm{CP}$, enabling a strong electrostatic attraction of the anionic groups of the dye [40]. However it must be emphasized that $\%$ $R M$ decreased in highly acidic medium $(\mathrm{pH}<4)$ because $\mathrm{CP}$ tend to dissolve under these conditions [39]. In general, RR-195 dye, is highly adsorbed under acidic and highly acidic conditions, as was reported in literature for modified switchgrass biochar $(\mathrm{pH}=5)$ [17], $\mathrm{TiO}_{2}$ nanoparticles $(\mathrm{pH}=3)[21]$, wheat bran [22] $(\mathrm{pH}=1.5)$, dehydrated beet 
a.

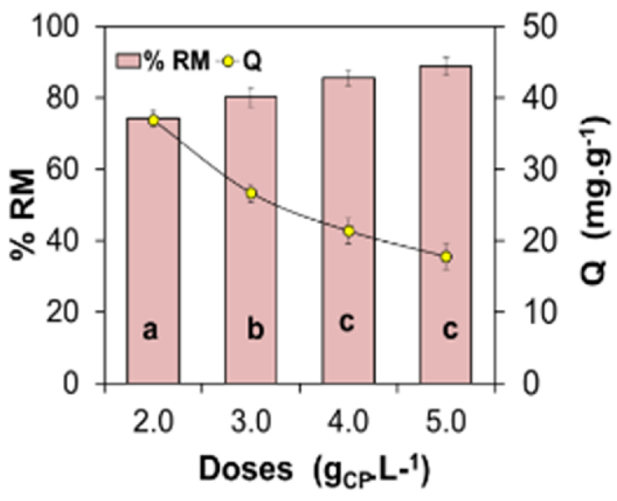

b.

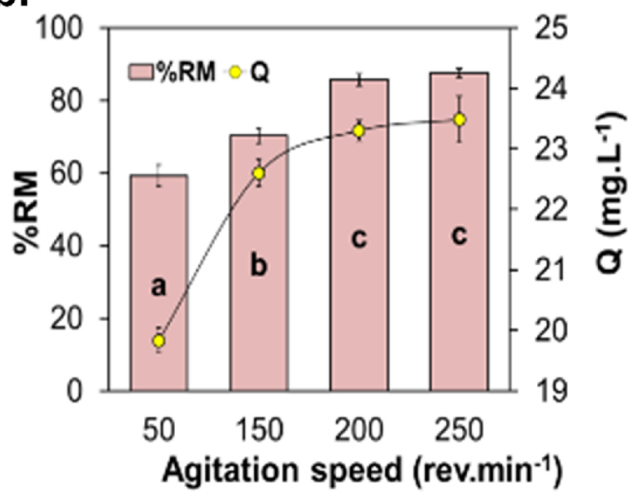

Fig. 2. Effects of different parameters on Dye removal (\%RM), adsorption capacity (Q) and Zeta Potential. a. Dosage of chitosan coacervated particles (CP); b. Agitation speed; c. pH. Experimental conditions Co $=100 \mathrm{mg} . \mathrm{L}^{-1}$; time $=12$ h: $\mathrm{T}=295 \mathrm{~K}$. Different letters in the $\%$ $\mathrm{RM}$ bars indicate significant differences between the samples ( $\mathrm{P} \leq 0.05)$.

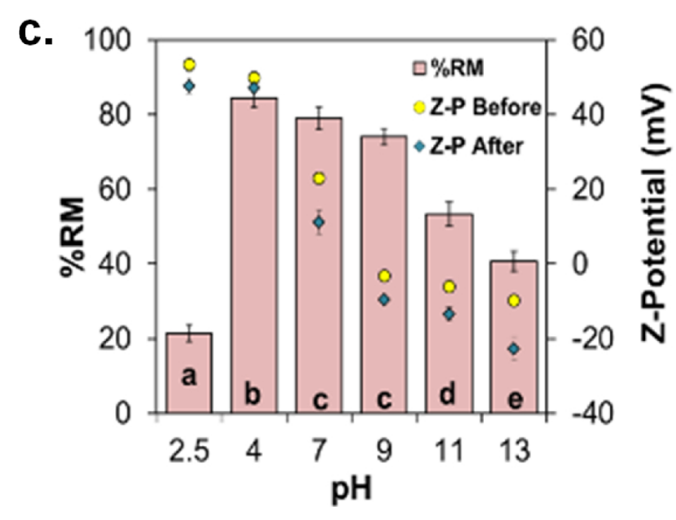

[23] and Pinus sylvestris L. biomass [26] $(\mathrm{pH}=1)$. It must be considered that the chemical structure of RR-195 presents sodium sulfonated groups $\left(-\mathrm{SO}_{3} \mathrm{Na}\right)$ which in acid solutions produces sulfonate anions $\left(-\mathrm{SO}_{3}{ }^{-}\right)$in this $\mathrm{pH}$ range.

The pKa of chitosan is 6.5 and the measured $\mathrm{pH}_{\text {IEP }}$ of the coacervated $\mathrm{CP}$ before and after adsorption ranged between 7 and 9 (Fig. 2c); in this range $\mathrm{CP}$ have a surface charge near to neutrality. ZP before and after adsorption was positive at $\mathrm{pH} \leq 7$ due to the presence of protonated amino groups. At alkaline $\mathrm{pH}$ the amino groups are not protonated and the ZP decreased to negative values before and after adsorption experiments; this decrease was more marked for CP after adsorption and can be attributed to the presence of the adsorbed dye containing sulfonated groups with negative charge.

The ZP values of $\mathrm{CP}$ before adsorption were higher than after adsorption; however the $\mathrm{pH}_{\mathrm{IEP}}$ remained at the same value, which implies that the adsorption process between the dye molecules and the CP is due to interactions of electrostatic nature [41] that can be reversible. The shift of the isoelectric point estimated through ZP measurements is an indicator of possible changes in the chemical structure of the adsorbent.

\subsection{Interactions between the bio-adsorbent and the dye}

\subsubsection{Morphology using SEM-EDS}

Fig. 3a corresponds to the chitosan coacervated particles (CP) after the dye adsorption. Fig. 3b shows a SEM micrograph of the surface of the bio-sorbent material after the adsorption process. The spectrum and mapping made with SEM-EDS (Fig. 3c) shows the presence of sulfur (S) on the surface of the $\mathrm{CP}$ which could only come from the dye molecule. Fig. $3 \mathrm{~d}$ shows cross sections of the spheres at different contact times with the dye.

\subsubsection{FTIR-ATR spectra}

FTIR-ART transmission spectra of: i) chitosan coacervated particles (CP), ii) chitosan particles after dye adsorption (CP + RR-195) and iii)
Reactive Red 195 (RR-195) are shown in Fig. 4a. In Fig. 4b the spectral zone 1600-1350 cm-1 was amplified.

For CP the main bands are: a) $3360 \mathrm{~cm}^{-1}$ corresponding to stretching vibrations of the $-\mathrm{OH}$ group, $-\mathrm{NH}$ group and hydrogen bonds, b) between 2920 and $2863 \mathrm{~cm}^{-1}$ symmetrical stretching of both the aliphatic $-\mathrm{CH}$ and the stretching vibration of the $\mathrm{C}-\mathrm{H}, \mathrm{c}$ ) at $1657 \mathrm{~cm}^{-1}$ stretching of the carbonyl group $\mathrm{C}=\mathrm{O}$, d) at $1551 \mathrm{~cm}^{-1}$ bending vibration of the amide II, which overlaps with the bending of the amino group at $1549 \mathrm{~cm}^{-1}[42,43]$, e) at $1420 \mathrm{~cm}^{-1}$ amide I group $\left(-\mathrm{NH}_{2}\right)$ and at $1374 \mathrm{~cm}^{-1}$ occurs the symmetrical bending vibration "scissor" of amide I, f) at $1156 \mathrm{~cm}^{-1}$ asymmetric bending vibration $\mathrm{C}-\mathrm{O}-\mathrm{C}, \mathrm{g}$ ) at $1060 \mathrm{~cm}^{-1}$ and $1020 \mathrm{~cm}^{-1}$ bands corresponding to the vibrations that involve stretching of the alcoholic group $\mathrm{C}-\mathrm{OH}$ characteristic of polysaccharides [44,45].

For the dye RR-195 the characteristic bands are: a) $3328-3650 \mathrm{~cm}^{-1}$ (stretching groups $-\mathrm{NH},-\mathrm{OH}$ and the resonant aromatic structure $=\mathrm{CH}$ ), b) $2915-2855 \mathrm{~cm}^{-1}$ (asymmetric stretching of the aliphatic $-\mathrm{CH}$ ), c) $1618 \mathrm{~cm}^{-1}$ (vibration of aromatic ring) [18], d) at $1587 \mathrm{~cm}^{-1}$ (stretching of $\mathrm{C}=\mathrm{N}$ ), e) at $1547 \mathrm{~cm}^{-1}$ (stretching of the azo group $-\mathrm{N}=\mathrm{N}-$ ) [46], f) at $1420 \mathrm{~cm}^{-1}$ the symmetric stretches $-\mathrm{N}-\mathrm{C}=$ $\mathrm{N}-, \mathrm{g}$ ) at 1492 and $1394 \mathrm{~cm}^{-1}$ (vibrational stretching of the $\mathrm{C}-\mathrm{N}$ ), h) at $1319 \mathrm{~cm}^{-1}$ (vibrations of group $\mathrm{S}=\mathrm{O}$ of $\mathrm{SO}_{2}$ ), i) at $1039 \mathrm{~cm}^{-1}$ (stretching of $-\mathrm{C}-\mathrm{OH}$ and / or $-\mathrm{CN}$ ) and $1180 \mathrm{~cm}^{-1}$ (vibrations of the phenolic $-\mathrm{C}-\mathrm{OH}$ group), j) $669 \mathrm{~cm}^{-1}$ stretching $-\mathrm{S}=\mathrm{O}$ [47].

The spectrum of CP with the adsorbed RR-195 (Fig. 4a) does not show shifting of the bands which could imply a new chemical bond between $\mathrm{CP}$ and the dye, however there is an incorporation of characteristic bands from the dye onto the $\mathrm{CP}$ spectra. The interactions of the amino groups $\left(-\mathrm{NH}_{3}{ }^{+}\right)$with the sulfonate group $\left(-\mathrm{SO}_{3}{ }^{-}\right)$of the dye, led to the following changes in the spectra: (i) weakening of the band around of $3360 \mathrm{~cm}^{-1}$ (intermolecular forces between the molecules present), (ii) at the end of the band $2863 \mathrm{~cm}^{-1}$ there is a decrease of the intensity of the shoulder [48] (iii) a new small band at $1490 \mathrm{~cm}^{-1}$ due to the vibrational stretching of the $\mathrm{C}-\mathrm{N}$ indicated a slightly shift of the original peak of the dye (RR-195) $\left(1942 \mathrm{~cm}^{-1}\right)$; this confirms that 

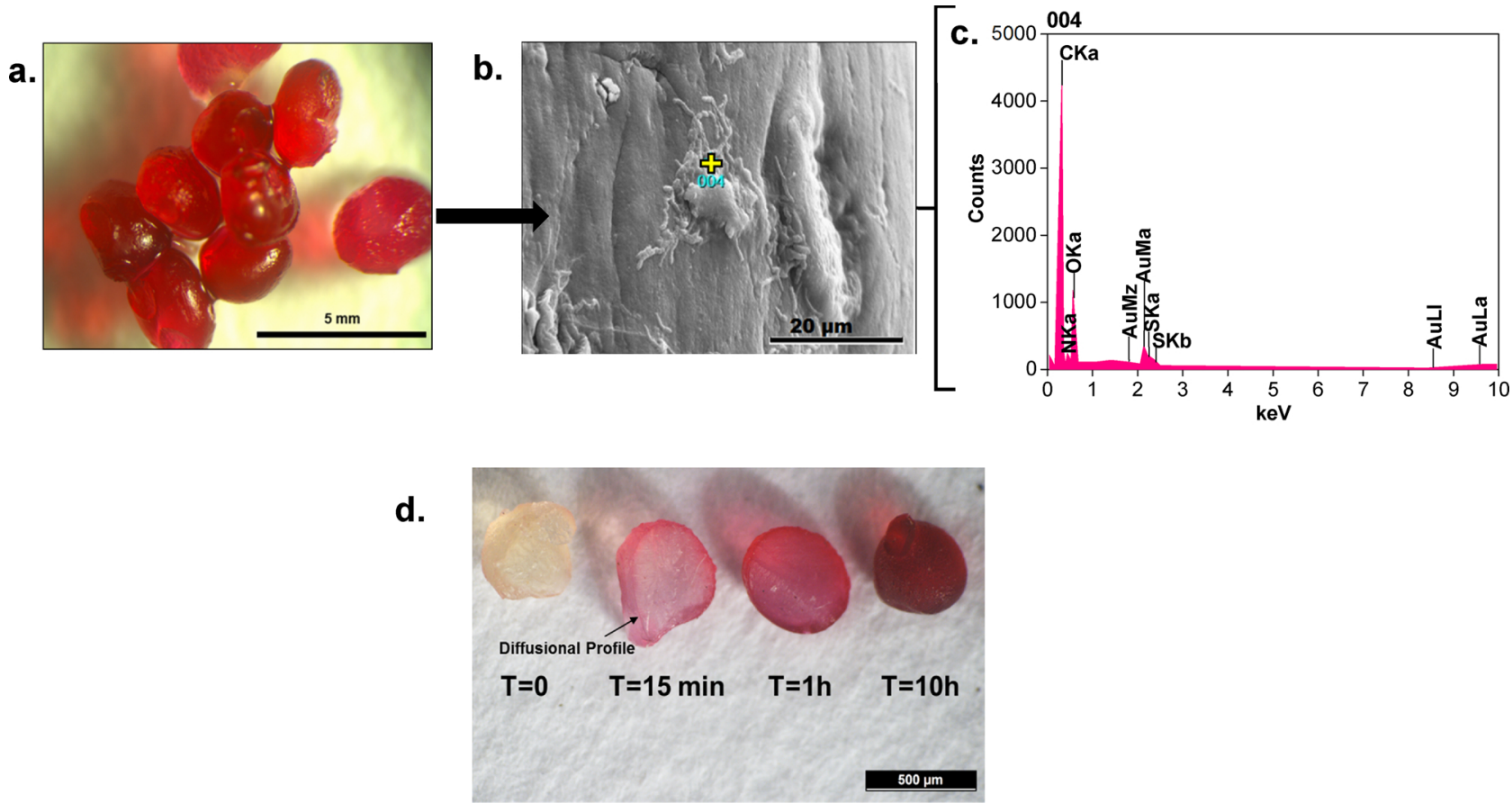

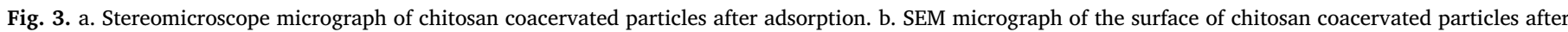
adsorption of the dye. c.EDS microanalysis spectrum. d. Cross sections of the coacervated chitosan particles in contact with the dye at different times.

the adsorption process occurs through hydrogen bonding and/or electrostatic interactions [18], (this new band can be observed by amplifying the spectral zone $1600-1350 \mathrm{~cm}^{-1}$ in Fig. 4b), (iv) weakening of the band at $1551 \mathrm{~cm}^{-1}$ due to the interaction of the free amino groups with the dye [49].

\subsection{Adsorption isotherm}

Table 3 shows the isotherm parameters calculated by each model using non-linear regressions (Langmuir, Freundlich, Temkin, D-R, R-P). In addition, the statistical indicators that reflect the goodness of fit of each equation are presented.

Langmuir isotherm described by Eq. 3 is a theoretical model for completely homogenous monolayer adsorption [50]. From Eq.3 the parameter $Q_{m}\left(\mathrm{mg} . \mathrm{g}^{-1}\right)$ is a constant that denotes the maximum adsorption capacity, while the constant $K_{L}\left(\mathrm{~L} \cdot \mathrm{mg}^{-1}\right)$ defines the affinity of the adsorbate for the adsorbent. The obtained values of $Q_{m}$ increased with temperature being $63.2 \mathrm{mg} \mathrm{g}^{-1}$ at $298 \mathrm{~K}, 76.2 \mathrm{mg} \mathrm{g}^{-1}$ at $308 \mathrm{~K}$ and $82.1 \mathrm{mg} \mathrm{g}^{-1}$ at $318 \mathrm{~K}$ (Table 3); these results showed that the adsorption process is favored at higher temperatures. Table 4 allows to compare for RR-195, results of the maximum monolayer adsorption capacity $\left(Q_{m}\right)$ (obtained by Langmuir model) of different types of adsorbents reported in literature. The $Q_{m}$ obtained in the present work for $\mathrm{CP}$ is among the top three adsorbent materials, in terms of adsorption capacity $\left(Q_{m}=82.1 \mathrm{mg} . \mathrm{g}^{-1}\right) ; Q_{m}=116.3 \mathrm{mg} \cdot \mathrm{g}^{-1}$ was reported by Çiçek et al., [22] at $\mathrm{pH}=1.5$ followed by Belessi et al. [21], with $Q_{m}=87 \mathrm{mg} \cdot \mathrm{g}^{-1}$ at $\mathrm{pH}=3$.

Eq.4 describes the Freundlich model, which assumes that there is heterogeneity of the active sites on the surface of the adsorbent [51]. The parameters of the Freundlich model are the adsorption capacity coefficient $K_{F}\left(\left(\mathrm{mg} . \mathrm{g}^{-1}\right)(\mathrm{mg} \cdot \mathrm{L})^{-1 / \mathrm{n}}\right)$ and the adsorption intensity (n). $K_{F}$ is the quantity of dye adsorbed onto an adsorbent in the equilibrium; the magnitude of $\mathrm{n}$ indicates the favorability of the process; when $\mathrm{n}>1$ the adsorption process is favorable, if $1<\mathrm{n}<10$ the material shows good adsorption properties [52]. Obtained values of $K_{F}$ and n, at different temperatures are shown in Table $3 . K_{F}$ increases with the increase of the temperature. For the three tested temperatures $n$ ranged between
3.6-3.1, therefore the material exhibits good adsorption properties; similar results were reported by Rojas-Garcia et al., [53].

The Temkin model assumes that the heat of adsorption decreases linearly with the increase of adsorbent-adsorbate interactions [54]. This model is expressed in Eq.5 where $B_{t}$ is the constant that is related to the heat of adsorption and $A_{t}$ (L. $\mathrm{mg}^{-1}$ ) is the equilibrium constant corresponding to the maximum binding energy.

The model D-R assumes two possible mechanisms (physical or chemical) for the adsorption process [55]. Eq. 6 represents this model, where $\varepsilon\left(\mathrm{kJ} \mathrm{mol}^{-1}\right)$ is Polanyi's potential, that is calculated as follows:

$\varepsilon=R \cdot T \cdot \operatorname{Ln}\left(1+\frac{1}{C_{e}}\right)$

where $R$ is the gas constant $\left(8.314 \times 10^{-3} \mathrm{~kJ}^{-1} \cdot \mathrm{mol}^{-1}\right), T$ is the temperature in $\mathrm{K}$. By previously calculating $K_{D R}$ it is possible to determine the average free adsorption energy $(E)$ using :

$E=1 /\left(2 . K_{D R}\right)^{0.5}$

where $E\left(\mathrm{~kJ} . \mathrm{mol}^{-1}\right)$ defines the mechanism of adsorption; if $E$ is $>8$ $\mathrm{kJ} \mathrm{mol}^{-1}$ the process is governed by the chemisorption, if $E<8$ $\mathrm{kJ} \mathrm{mol}^{-1}$ the mechanism is physisorption [55]. Values of $E$ (Table 3) indicates that the process is governed by physisorption.

The R-P model is an empirical equation incorporating features of the Freundlich and Langmuir models [56]. Eq. 7 describes this isotherm

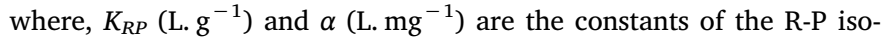
therm and $\beta$ is an exponent with values ranging between 0 and 1 . According to the statistical parameters, R-P was the model that best fitted the experimental data. Experimental and predicted values are shown In Fig. 5a. The $\% D P$ calculated was $\pm 5.5 \%$ at $308 \mathrm{~K}$ using R-P (Fig. $5 \mathrm{~b}$ ).

The R-P model has been widely used to explain the phenomena of dye adsorption $[33,57,58]$. In the cases of adsorbents based on chitosan Wong et al. [59], evaluated the action of chitosan powder in the adsorption of 5 acid azo dyes; Dotto et al. [60], used chitosan films for the adsorption of food azo dyes; Juang et al. [61] studied adsorption of three reactive azo dyes (Reactive Red 222, Reactive Yellow 145 and Reactive Blue 222). 

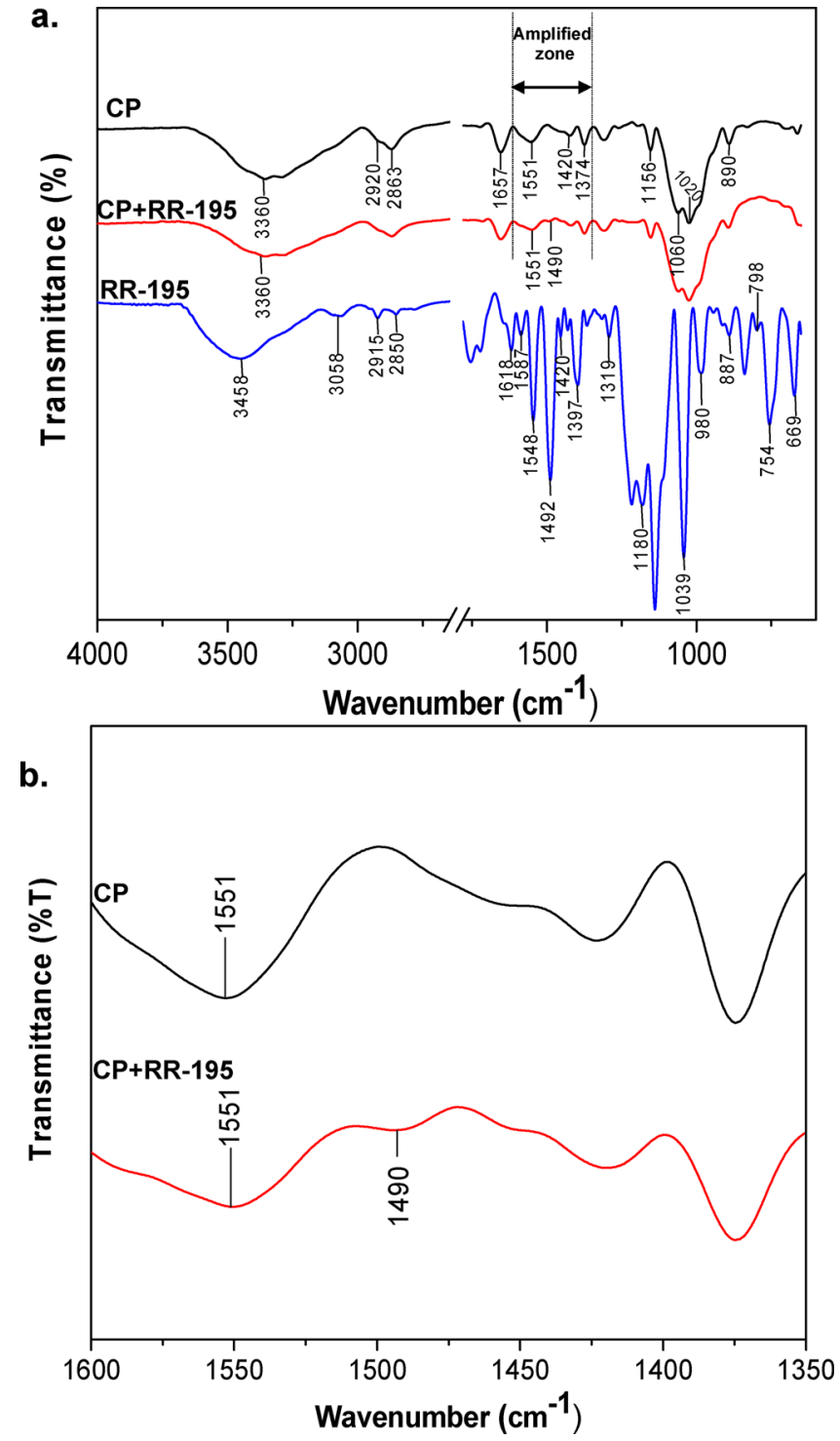

Fig. 4. FTIR-ART transmission spectra of: a. chitosan coacervated particles (CP), chitosan particles after adsorption of dye (CP + RR-195) and Reactive Red 195 (RR-195). b. Amplified zone 1600-1350 $\mathrm{cm}^{-1}$.

\subsection{Adsorption Thermodynamic parameters}

Thermodynamic parameters were calculated by studying the adsorption of RR-195 at different temperatures. The Van't Hoff equation (Eq.9) was applied:

$\operatorname{Ln} K_{C}=-\frac{\Delta H}{R T}+\frac{\Delta S}{R}$

where $K_{C}$ corresponds to the equilibrium distribution constant, $R$ is the
Table 4

Maximum monolayer adsorption capacities $\left(Q_{m}\right)$ of different materials used in the adsorption of RR-195.

\begin{tabular}{|c|c|c|c|}
\hline Adsorbent & $\begin{array}{l}Q_{m} \\
\left(\mathrm{mg} \cdot \mathrm{g}^{-1}\right)\end{array}$ & Conditions & Reference \\
\hline Wheat bran & 116.3 & $\begin{array}{l}313 \mathrm{~K}, \mathrm{pH}=1.5 \\
24 \mathrm{~h}\end{array}$ & [22] \\
\hline Nanoparticles $\mathrm{TiO}_{2}$ & 87 & $\begin{array}{l}303 \mathrm{~K}, \mathrm{pH}=3 \\
1 \mathrm{~h}\end{array}$ & [21] \\
\hline Chitosan coacervated particles & 82.1 & $\begin{array}{l}318 \mathrm{~K}, \mathrm{pH}=4 \\
10 \mathrm{~h}\end{array}$ & Present study \\
\hline Dehydrated beet pulp carbon & 58 & $\begin{array}{l}325 \mathrm{~K}, \mathrm{pH}=1,2 \\
\mathrm{~h}\end{array}$ & [23] \\
\hline Palygorskite modified & 34 & $293 \mathrm{~K}, 35 \mathrm{~min}$ & [24] \\
\hline Modified Switchgrass Biochar & 27.02 & $\begin{array}{l}298 \mathrm{~K}, \mathrm{pH}=5, \\
1 \mathrm{~h}\end{array}$ & [17] \\
\hline Rice husk & 12.2 & $303 \mathrm{~K}, 2 \mathrm{~h}$ & [25] \\
\hline Biomass of Pinus sylvestris $L$. & 6.39 & $\begin{array}{l}323 \mathrm{~K}, \mathrm{pH}=1,3 \\
\mathrm{~h}\end{array}$ & {$[26]$} \\
\hline $\begin{array}{l}\text { Cotton woven fabric in a nonionic } \\
\text { surfactant Triton X-100 }\end{array}$ & 2.92 & $293 \mathrm{~K}, 5 \mathrm{~h}$ & [27] \\
\hline
\end{tabular}

universal constant of gases $\left(8.314 \times 10^{-3} \mathrm{~kJ} \cdot \mathrm{mol}^{-1} \cdot \mathrm{K}^{-1}\right), \Delta H$ is the enthalpy, $\Delta S$ the entropy, and $\mathrm{T}$ is the temperature of the experiment given in Kelvin. $K_{C}$ has been applied for the calculation of thermodynamic parameters of dye absorption [62-65]. $K_{C}$ can be calculated as:

$K_{C}=\frac{a_{s}}{a_{e}}=\frac{\gamma_{s} C_{s}}{\gamma_{e} C_{e}}$

where $a_{s}$ is the activity of the dye adsorbed by the solid and $a_{e}$ are activity of the dye in the solution at equilibrium. $\gamma_{s}$ and $\gamma_{e}$ are the corresponding activity coefficients and $\mathrm{Cs}$ and $\mathrm{Ce}$ are the concentrations expressed in mg.L ${ }^{-1}$. Cs is calculated as $C_{i}{ }^{-} C_{e}$, where $C_{i}$ is the initial concentration of dye in the system. The activity coefficient $(\gamma)$ approaches unity when the equilibrium concentration $(C s) \lambda 0$ and $(C e)$ $\lambda 0$, therefore Eq. (11) can be written as:

$\lim _{C_{S} \rightarrow 0} \frac{C_{S}}{C_{e}}=\frac{a_{s}}{a_{e}}=K_{C}$

$K_{C}$ can be determined plotting $\operatorname{Ln}(C s / C e)$ vs $C s$ at each experimental temperature [64]; from the linear regressions, $\operatorname{Ln}\left(K_{C}\right)$ values were obtained from the intercepts (results of these plots are shown in supplementary material S2.a). According to Eq. 9 by plotting Ln $\left(K_{C}\right)$ as a function of $\mathrm{T}^{-1}, \Delta H$ and $\Delta S$ were determined (supplementary material S2.b). The results are shown in Table 5; the Gibbs free energy $(\Delta G)$ was calculated using Eq. 12

$\Delta G=\Delta H-T \Delta S$

The adsorption of dye onto $\mathrm{CP}$ showed negative values of $\Delta G$, indicating that it is a spontaneous and favorable process. Negative values of $\Delta G$ indicate that the material has a high adsorption capacity [66]. $\Delta H$ was positive; therefore the process is endothermic [67]; thus the increase of temperature favors the adsorption of RR-195.

The thermodynamic parameters can reflect the adsorption characteristics of the process $[19,45,68] ; \Delta H<20.9 \mathrm{~kJ} . \mathrm{mol}^{-1}$ and absolute

Table 3

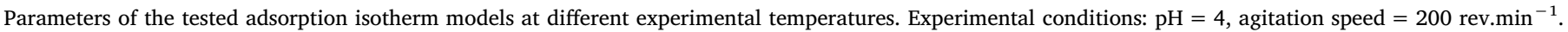

\begin{tabular}{|c|c|c|c|c|c|c|c|c|c|c|c|c|c|c|c|c|c|c|c|c|c|c|c|c|c|c|c|}
\hline \multirow[t]{2}{*}{$\mathrm{T}(\mathrm{K})$} & \multicolumn{5}{|c|}{ Langmuir } & \multicolumn{5}{|c|}{ Freundlich } & \multicolumn{5}{|c|}{ Temkin } & \multicolumn{6}{|c|}{ Redlich-Peterson } & \multicolumn{6}{|c|}{ Dubinin-Radushkevich } \\
\hline & $Q_{m}$ & $K_{L}$ & $\chi^{2}$ & $R^{2}$ & $\% e$ & $K_{F}$ & $n$ & $\chi^{2}$ & $R^{2}$ & $\% e$ & $A_{t}$ & $B_{t}$ & $\chi^{2}$ & $R^{2}$ & $\% e$ & $K_{R-P}$ & $\alpha$ & $\beta$ & $\chi^{2}$ & $R^{2}$ & $\% e$ & $Q_{D-R}$ & $K_{D R}$ & $E \times 10^{-2}$ & $\chi^{2}$ & $R^{2}$ & $\% e$ \\
\hline 298 & 63.2 & 0.1 & 17 & 0.96 & 9.4 & 14.7 & 3.6 & 16 & 0.96 & 5 & 2.8 & 10 & 19 & 0.95 & 1.8 & 12.2 & 0.4 & 0.8 & 9 & 0.97 & 4.3 & 65.7 & 82 & 7.8 & 35 & 0.92 & 12.7 \\
\hline 308 & 76.2 & 0.1 & 34 & 0.95 & 5.2 & 16.6 & 3.2 & 25 & 0.96 & 6.6 & 2.8 & 12 & 37 & 0.94 & 1.4 & 19.8 & 0.6 & 0.8 & 18 & 0.98 & 3.3 & 77 & 91 & 7.4 & 65 & 0.90 & 17,2 \\
\hline 318 & 82.1 & 0.2 & 54 & 0.93 & 5.8 & 18.3 & 3.1 & 24 & 0.97 & 6.7 & 3.4 & 13 & 47 & 0.94 & 2.4 & 59.5 & 2.5 & 0.7 & 3 & 0.98 & 1.7 & 83.6 & 112 & 7.4 & 89 & 0.90 & 20.1 \\
\hline
\end{tabular}

Units of the parameters used in the isotherm models.

$Q_{m}\left[\mathrm{mg} . \mathrm{g}^{-1}\right] K_{L}\left[\mathrm{~L} \cdot \mathrm{mg}^{-1}\right] K_{F}\left[\left(\mathrm{mg} \cdot \mathrm{g}^{-1}\right)(\mathrm{mg} \cdot \mathrm{L})^{-1 / \mathrm{n}}\right] A_{t}\left[\mathrm{~L} \cdot \mathrm{mg}^{-1}\right] K_{R-P}\left[\mathrm{~L} \cdot \mathrm{g}^{-1}\right] \alpha\left[\left(\mathrm{L} \cdot \mathrm{mg}^{-1}\right) \beta\right] Q_{D-R}\left[\mathrm{mg} \cdot \mathrm{g}^{-1}\right] K_{D R}\left[\mathrm{~kJ} J^{2} \cdot \mathrm{mol}^{2}\right] E\left[\mathrm{~kJ} \cdot \mathrm{mol}^{-1}\right]$. 


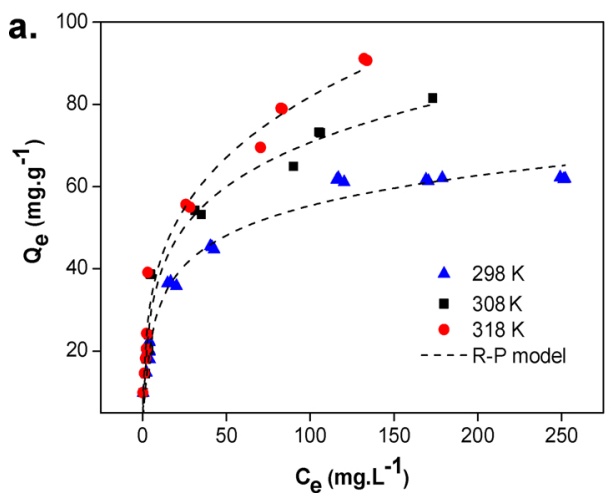

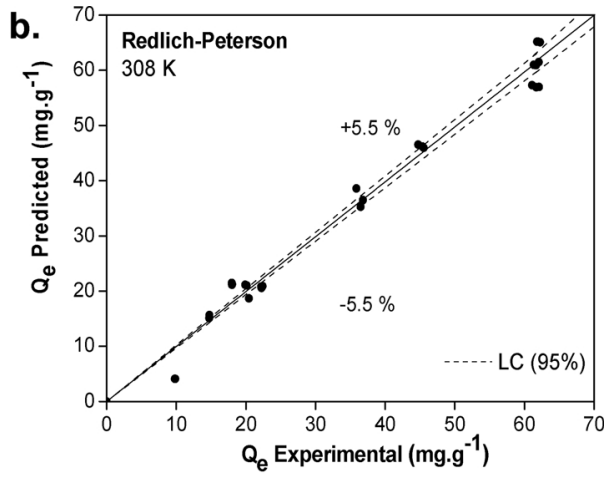

Fig. 5. a. Adsorption isotherms of Reactive Red 195 onto chitosan coacervated particles at different temperatures; symbols represent experimental values and dash lines correspond to the fitting of the nonlinear regression using RedlichPeterson model (R-P). Experimental conditions: $\mathrm{pH}=4$, agitation speed $=$ 200 rev.min ${ }^{-1}, 0.2 \mathrm{~g}$ of chitosan coacervated particles. b. Predicted values from R-P model versus experimental results were plotted to determine the range that contains $95 \%$ of the data (\% $D P)$.
Table 5

Thermodynamic parameters. The errors of the parameters are given between parentheses and correspond to Standard Deviations ( \pm SD).

\begin{tabular}{llll}
\hline $\begin{array}{l}\text { Temperature } \\
(\mathrm{K})\end{array}$ & $\begin{array}{l}\Delta G \\
\left.\mathrm{kJJ} . \mathrm{mol}^{-1}\right)\end{array}$ & $\begin{array}{l}\Delta H \\
\left(\mathrm{~kJ} . \mathrm{mol}^{-1}\right)\end{array}$ & $\begin{array}{l}\Delta S \\
\left(\mathrm{~kJ} . \mathrm{mol}^{-1} \cdot \mathrm{K}^{-1}\right)\end{array}$ \\
\hline 298 & $-10.04( \pm 1.8)$ & $20.7( \pm .1 .7)$ & $0.10\left( \pm 6 \times 10^{-3}\right)$ \\
308 & $-10.55( \pm 1.8)$ & & \\
318 & $-12.10( \pm 1.9)$ & & \\
\hline
\end{tabular}

values of $\Delta G<40 \mathrm{~kJ} \cdot \mathrm{mol}^{-1}$ indicate that physisorption occurs [68]. The affinity of the RR-195 molecules for the CP was corroborated by the positive values of $\Delta S$, showing that the process is randomly increasing the degrees of freedom of the adsorbed species at the adsorbent-adsorbate interface $[63,66]$.

Several works that used RR-195 also obtained negative $\Delta G$ values with endothermic and positive entropy change processes. Aksakal and Ucun [26] reported that the mechanism of adsorption of RR-195 by Pinus sylvestris L. was physisorption $\left(\Delta H=29.4 \mathrm{~kJ}^{\mathrm{mol}}{ }^{-1}\right)$, being endothermic and spontaneous with negative values of $\Delta G(\Delta \mathrm{G}=$ $14.02 \mathrm{~kJ} \cdot \mathrm{mol}^{-1}$ at $\left.303 \mathrm{~K}\right)$ and $\Delta S$ positive $\left(0.144 \mathrm{~kJ} \cdot \mathrm{mol}^{-1} \cdot \mathrm{K}^{-1}\right)$. Dursun and Tepe [23] established that the adsorption process of RR-195 using dehydrated beet pulp carbon is spontaneous $(\Delta G$ at $298 \mathrm{~K}=$ $\left.-29.5 \mathrm{~kJ} . \mathrm{mol}^{-1}\right)$ and endothermic $\left(\Delta H=16 \mathrm{~kJ} . \mathrm{mol}^{-1}\right)$, for this case $\Delta S$ was $0.15 \mathrm{~kJ} . \mathrm{mol}^{-1} \cdot \mathrm{K}^{-1}$. Çiçek et al., [22] reported different thermodynamic parameters for the adsorption of three reactive azo dyes (Reactive Blue 19, Reactive Red 195 and Reactive Yellow 145) using wheat bran; for these three dyes $\Delta G$ was negative and increased with temperature $\left(\Delta \mathrm{G}=-27.7\right.$ to $\left.-31 \mathrm{~kJ} . \mathrm{mol}^{-1}\right) ; \Delta H=6.72 \mathrm{~kJ} . \mathrm{mol}^{-1}$ and $\Delta S$ was positive, for RR-195 $\left(0.11 \mathrm{~kJ} \cdot \mathrm{mol}^{-1} . \mathrm{K}^{-1}\right)$. Similar results were reported for chitosan coacervated beads for the adsorption of Reactive Black 5, with $\Delta \mathrm{G}$ ranging between -29 and $-41 \mathrm{~kJ} \cdot \mathrm{mol}^{-1}, \Delta S$ and $\Delta H$ both positive, being the latter value $\Delta H=52 \mathrm{~kJ} \mathrm{~mol}^{-1}$ [44]. In the present work the estimated thermodynamic parameters are in the range of physisorption.

\subsection{Adsorption kinetics}

The adsorption kinetic curves are shown in Fig. 6. After $10 \mathrm{~h}$ the adsorption equilibrium reached a high \%RM. For example at an initial $C_{O}=300 \mathrm{mg} . \mathrm{L}^{-1}$ the $\% R M$ was $84.2 \pm 0.6$ using $0.20 \mathrm{~g}$ of CP (Fig. 6a). The kinetic curves of the bio-sorbent at $298 \mathrm{~K}$ and $\mathrm{pH}=4$ are shown in Fig. 6b.

In Table 2, Eq.9 describes the Pseudo first order (PS1) [69], where $k_{1}\left(\mathrm{~min}^{-1}\right)$ is the rate constant of the first-order adsorption and $Q_{e}$ (mg. $\mathrm{g}^{-1}$ ) is the equilibrium adsorption capacity. The Pseudo second order model (PS2) is given by Eq.10 where $k_{2}\left(\mathrm{~g} \cdot \mathrm{mg}^{-1} \cdot \mathrm{min}^{-1}\right)$ is the second-order rate constant [70]. The Elovich model (Eq. (11)) assumes that the active sites are heterogeneous and therefore exhibit different activation energies where $\alpha$ (mg. $\mathrm{g}^{-1}$. $\mathrm{min}^{-1}$ ) corresponds to the initial adsorption rate and $\beta$ is related to the surface coverage and activation energy [71].

The intraparticle diffusion model (Eq. (12)) is based on the diffusion of the adsorbate and has been widely used in chitosan hydrogels [19]. The equation can be applied in both regions of the kinetic curve [72,73] that correspond to: (i) the initial stage where there is a rapid external diffusion and surface adsorption, ii) second stage where the intraparticle diffusion is the controlled step.

The mixed surface reaction and diffusion-controlled kinetic model (MSR-DCK) (Eq.13) reported by Haerifar and Azizian [74] was also applied. This adsorption kinetic model includes both phenomena occurring simultaneously: diffusion of the dye molecules in the system and adsorption in the active sites of the adsorbent matrix.

The kinetic equation is given by:

$\frac{d C}{d t}=-k^{\prime}\left(1+\frac{\tau^{1 / 2}}{t^{1 / 2}}\right) C\left(q_{e}-q\right)$

where $C$ is the concentration of the solute in the bulk phase at any time and diminishes during of adsorption process; $q$ is the amount of adsorbed solute per unit mass of adsorbent, $q=(V / m)\left(C_{0}-C\right)$, ( $V$ is the solution volume, $m$ is the adsorbent mass, $q_{e}$ is the equilibrium value, $C_{o}$ is the initial concentration of the adsorbent in the solution); $C_{e}$ is the concentration at equilibrium; $\tau$ is a characteristic time which is inversely proportional to the adsorbate diffusion coefficient. This model considers that $\left(q_{e}-q\right)$ is proportional to the number of available empty sites on the adsorbent at any time. At any time from a mass balance the following is obtained [74]:

$C=C_{0}-\beta . q$

where $\beta=\left(\left(C_{0^{-}} C_{e}\right) / q_{e}\right)$, and substituting in the differential equation (Eq.13) the following expression is obtained in terms of $q$ as:

$\frac{d q}{d t}=k\left(1+\frac{\tau^{\frac{1}{2}}}{t^{\frac{1}{2}}}\right)\left(C_{0}-\beta q\right)\left(q_{e}-q\right)$

where $k=\left(k^{\prime} / \beta\right)$.

The analytical solution of the ordinary differential equation was reported by Haerifar and Azizian [74], and the obtained expression is:

$Q=Q_{e} \frac{\exp ^{\left(a . t+b . t^{0.5}\right)}-1}{\left(w_{e q} \cdot \exp ^{\left(a . t+b . t^{0.5}\right)}-1\right)}$

where $w_{e q}=1-\left(C_{e} / C_{0}\right)$ represents the relative equilibrium uptake $\left(0 \leq w_{e q} \leq 1\right), b=2 \cdot k \cdot C_{0} \cdot \tau^{0.5} \cdot\left(w_{e q}-1\right)$ and $a=k \cdot C_{0} \cdot\left(w_{e q}-1\right)$. This model considers both diffusion and adsorption as the rate-controlling steps. The effect of diffusion was introduced by the coefficient $b$ that contains the characteristic time, $\tau$ and the effect of adsorption by both $b$ and $a$ coefficients. The coefficients $a$ and $b$ of Eq. 16 were calculated by nonlinear regression of $Q$ as a function of time; from the ratio $\mathrm{b} / \mathrm{a}=2 . \tau^{0.5}$ the values of $\tau$ were determined

Table 6 shows the kinetic parameters calculated by non-linear 
a.
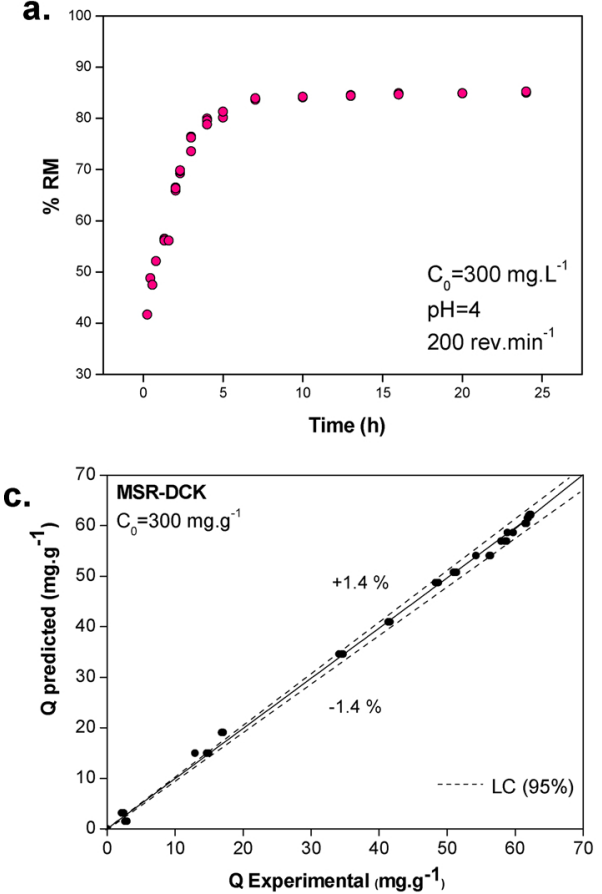

b.
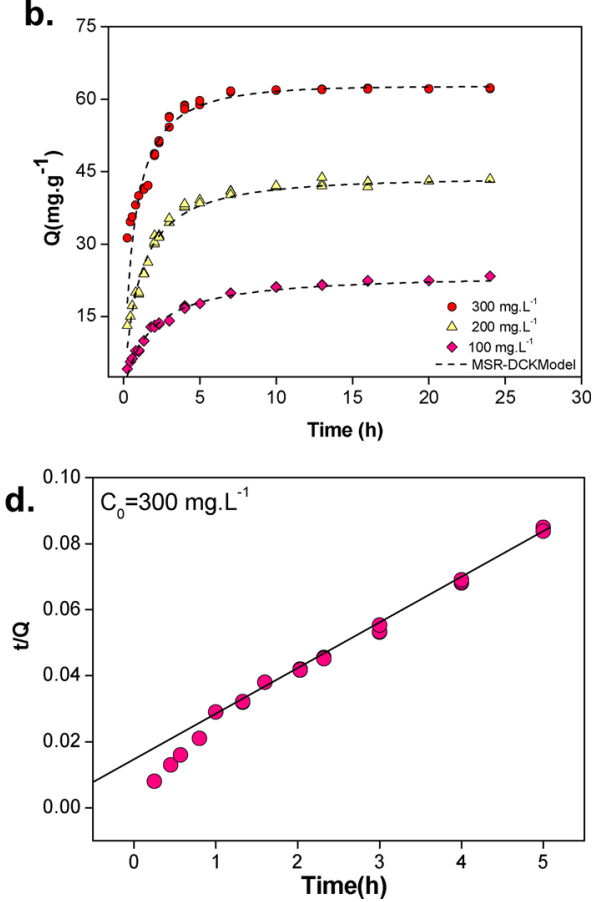

Fig. 6. a. Effect of contact time on dye removal $(\% R M)$, b. Adsorption kinetics of Reactive Red 195 onto coacervated chitosan particles at different initial concentrations. Experimental conditions: $\mathrm{pH}=4$, agitation speed $=200$ rev.min-1, mass of chitosan particles $=0.2 \mathrm{~g}, \mathrm{~T}=298 \mathrm{~K}$. Symbols represent experimental values, and dash lines correspond to the fitting of the non-linear regressions mixed surface reaction and diffusion-controlled kinetic model (MSR-DCK). c. Predicted versus experimental values showing the $\%$ of deviation (\%DP). d. Plot of $t /$ $Q_{t}$ vs time showing deviations from linearity at the initial times of adsorption due to a diffusion-controlled mechanism. regressions of the models (PS1, PS2, Elovich, intraparticle diffusion and MSR/DCK); the statistical indicators that reflect the goodness of fit are presented. The model with the best fit was MSR-DCK; in Fig. 6b, the experimental and the predicted values calculated with the selected model are shown. The $\% D P$ calculated was $\pm 1.4 \%$ using MSR-DK model (Fig. 6c).

The MSR-DCK indicates that there are two mechanisms that govern the process: the diffusion of the dye and the simultaneous adsorption in the active sites [74]. In Fig. 6d the plot of $t / Q$ vs time is shown according to Haerifar and Azizian [74]; in this graph a downward curvature at initial times of adsorption process can be observed. This deviation from linearity is produced when values of $\tau>0$ were obtained (Table 6). As can be observed in Fig. 6d diffusion contributes to the rate-controlling step of adsorption during the first hour.

In the adsorption process the swelling degree (\%SD) of the CP was $180 \pm 12 \%$ and the final mean diameter was $2.4 \pm 0.8 \mathrm{~mm}$ after adsorption, evidencing that the bio-adsorbent behaves like a hydrogel without collapsing its structure.

In Fig. 3d the cross sections of the spheres in contact with the dye show that after $15 \mathrm{~min}$, dye profiles are formed in the hydrogel confirming that diffusion of dye is the rate-controlling step; however, after $1 \mathrm{~h}$ a uniform distribution of colorant in the $\mathrm{CP}$ is detected.

Absorbance spectral scanning of the dye solution after adsorption was carried out at different times during the kinetics study (Supplementary material, S3), verifying that the dye does not undergo chemical decomposition reactions due to the fact that the position of the maximum absorbance length remained constant $(538 \mathrm{~nm}$ for the case of RR-195).

\subsection{Desorption/Regeneration}

The regeneration of the bio-sorbent is an important stage in order to recover dye and enables the reuse of the material for the consecutive cycles of adsorption. The regeneration of bio-adsorbents using chitosan can be carried out by changing the $\mathrm{pH}$ of the medium to alkaline [75] or by using solvents such as ethanol [76].

To analyze the regeneration of the adsorbent, the CP desorption method selected was based on the change of the solution $\mathrm{pH}$ to 12 . The desorption capacity $\left(Q_{D}\right)$ of the CP was calculated with Eq.14. In Fig. 7a the results of adsorption and desorption cycles are presented. During

Table 6

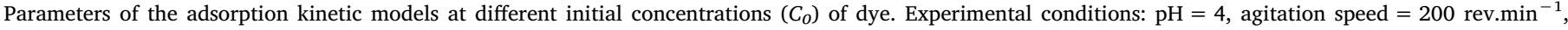
$\mathrm{T}=298 \mathrm{~K}$.

\begin{tabular}{|c|c|c|c|c|c|c|c|c|c|c|c|c|c|c|c|}
\hline \multirow[t]{2}{*}{$\mathrm{C}_{0}$} & \multicolumn{5}{|c|}{ Ps1 order } & \multicolumn{5}{|c|}{ Ps2 order } & \multicolumn{5}{|c|}{ Elovich } \\
\hline & $Q_{e}$ & $k_{1}$ & $\chi^{2}$ & $R^{2}$ & $\% e$ & $Q_{e}$ & $k_{2}$ & $\chi^{2}$ & $\mathrm{R}^{2}$ & $\% e$ & $\beta$ & $\alpha$ & $\chi^{2}$ & $R^{2}$ & $\% e$ \\
\hline 100 & 22.04 & 0.38 & 1.0 & 0.98 & 25 & 25.6 & 0.02 & 0.7 & 0.99 & 38 & 0.17 & 18.1 & 2.4 & 0.96 & 55 \\
\hline 200 & 42.59 & 0.56 & 3.2 & 0.99 & 81 & 48.24 & 0.01 & 7.6 & 0.97 & 19 & 0.1 & 59.0 & 23 & 0.90 & 151 \\
\hline 300 & 62.27 & 0.7 & 8.2 & 0.98 & 32 & 69.52 & 0.01 & 23 & 0.95 & 47 & 0.07 & 126 & 70 & 0.85 & 70 \\
\hline \multirow[t]{2}{*}{$\mathrm{C}_{0}$} & \multicolumn{10}{|c|}{ Intraparticle diffusion } & \multicolumn{5}{|l|}{ MSR/DCK } \\
\hline & $k_{D 1}$ & $c 1$ & $\chi^{2}$ & $R^{2}$ & $\% e$ & $k_{D 2}$ & $c 2$ & $\chi^{2}$ & $R^{2}$ & $\% e$ & $k \times 10^{-3}$ & $\tau$ & $\chi^{2}$ & $R^{2}$ & $\% e$ \\
\hline 100 & 11.68 & -4.41 & 0.9 & 0.97 & 23 & 2.2 & 13.2 & 0.6 & 0.89 & 12 & 7.55 & 0.033 & 0.3 & 0.95 & 5 \\
\hline 200 & 26.36 & -10.1 & 3.1 & 0.98 & 52 & 2.43 & 32.6 & 1.4 & 0.81 & 15 & 7.34 & 0.051 & 0.3 & 0.99 & 4.8 \\
\hline 300 & 44.18 & -15.4 & 15 & 0.96 & 26 & 1.18 & 57.2 & 0.8 & 0.64 & 18 & 6.94 & 0.055 & 1.4 & 0.97 & 3.6 \\
\hline
\end{tabular}

Units of the parameters used in the kinetic models.

$C_{O}\left[\mathrm{mg} \cdot \mathrm{L}^{-1}\right] Q_{e}\left[\mathrm{mg} . \mathrm{g}^{-1}\right] k_{1}$ y $k_{2}\left[\mathrm{~min}^{-1}\right] \beta\left[\mathrm{g} \cdot \mathrm{mg}^{-1}\right] \alpha\left[\mathrm{mg} \cdot \mathrm{g}^{-1} \cdot \mathrm{min}^{-1}\right] k_{D 1}$ y $k_{D 2}\left[\mathrm{mg} \cdot\left(\mathrm{g} \cdot \mathrm{min}^{0.5}\right)^{-1}\right] k\left[\mathrm{~L} \cdot \mathrm{mg}^{-1} \cdot \mathrm{min}{ }^{-1}\right] \tau[\mathrm{min}]$ 

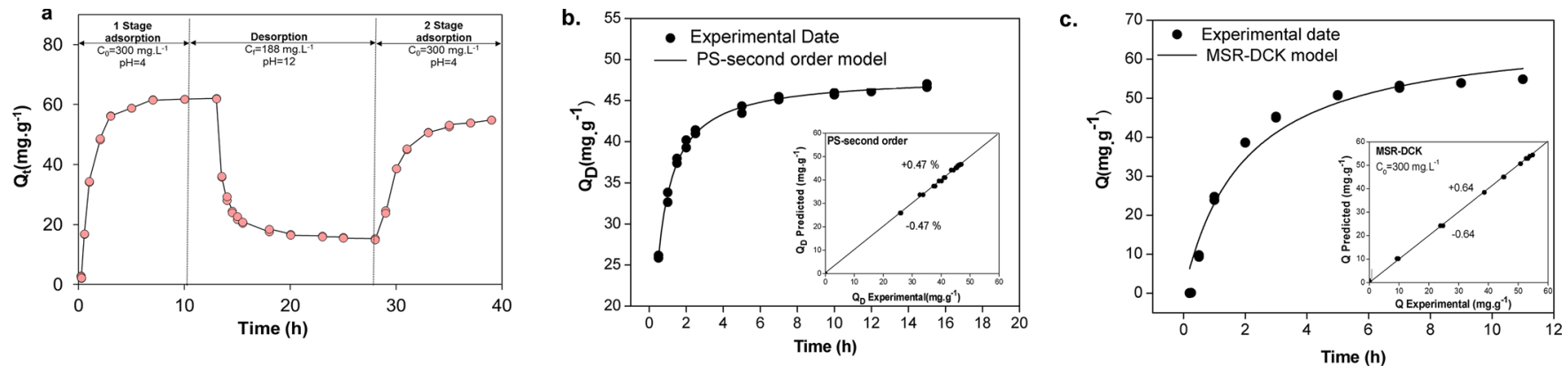

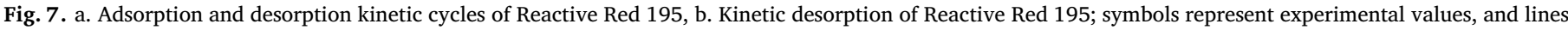

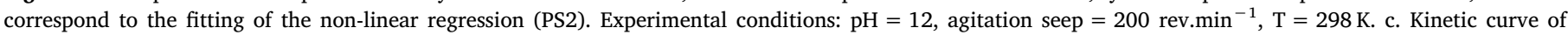

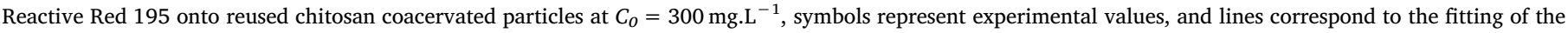

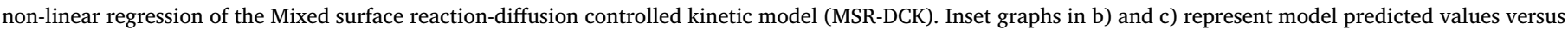
experimental results showing the $\%$ of deviation $(\% D P)$.

the desorption cycle, the kinetics was analyzed; PS2 was the model that best fit the experimental data (Fig. 7b). The parameters obtained were: $Q_{e}=47.96 \mathrm{mg} \cdot \mathrm{g}^{-1}$ and $k_{2}=0.05 \mathrm{~min}^{-1}\left(\chi^{2}=0.17, R^{2}=0.996\right.$ and $\% e=0.14$ ).

During desorption, the alkaline $\mathrm{pH}$ produced deprotonation of the amino groups, causing the electrostatic interactions between the chitosan and the dye to decrease [77]. A high dye removal of the bio-adsorbent matrix was achieved reaching $75.53 \%$. The second adsorption cycle was carried out at $\mathrm{pH}=4$ with a $C_{0}=300 \mathrm{mg} . \mathrm{L}^{-1}$, the model that best fit the experimental data was MSR-DCK (the same as in the first cycle), and the parameters calculated were: $k=4.59 \times 10^{-3} \mathrm{~L}$. $\mathrm{mg}^{-1} . \mathrm{min}^{-1}$ and $\tau=0.058 \mathrm{~min}\left(\chi 2=0.31, R^{2}=0.999\right.$ and $\left.\% e=10\right)$ (Fig. 7c). The second adsorption cycle reached a $Q_{e}=47.96 \mathrm{mg}^{-g^{-1}}$, lower than in the first cycle $\left(Q_{e}=62.27 \mathrm{mg} . \mathrm{g}^{-1}\right)$ therefore it can be concluded that there was a $23 \%$ reduction in the adsorption capacity. The $\% R M$ in the second adsorption cycle was $73.27 \%$ (compared to $84.48 \%$ from the first cycle). Equilibrium during adsorption was reached after $10 \mathrm{~h}$, for both adsorption cycles. These results indicate that $\mathrm{CP}$ are materials that can be subjected to regeneration and reuse for the adsorption of RR-195.

\section{Conclusions}

The adsorption of RR-195 azo dye using coacervated chitosan particles (CP) as bio-sorbent in batch experiments was tested. This material was obtained using the technique of coacervation in an alkaline medium. The morphology of the bio-sorbent and microstructural properties of the $\mathrm{CP}$ before adsorption were determined; experimental data showed that the pore size distribution were in the range of mesopore materials. Different experimental conditions (doses of bio-adsorbent, initial $\mathrm{pH}$, temperatures and reaction time) for RR-195 removal were investigated; the maximum $\% R M$ was evidenced at $\mathrm{pH}=4$, which constitutes a benefit in terms of working conditions during adsorption processes, since it is a higher $\mathrm{pH}$ compared to other reported bio-absorbers where the removal of RR-195 requires very high acidic conditions $(\mathrm{pH}<<4)$

Different adsorption isotherms were tested through non-linear regressions; the Redlich-Peterson model presented the best fit (for example at $\mathrm{T}=318 \mathrm{~K}, \chi^{2}=54, R^{2}=0.93, \% e=3.3$ and $\% D P= \pm 5.8$ ); in this case the maximum monolayer adsorption capacity $\left(Q_{m}\right)$ was $82.1 \mathrm{mg} \cdot \mathrm{g}^{-1}$ at $\mathrm{pH}=4$ and $318 \mathrm{~K}$. From the adsorption thermodynamic parameters, it can be concluded that the adsorption process of RR-195 onto $\mathrm{CP}$ is spontaneous, favorable $(\Delta G<0)$, endothermic $(\Delta H>0)$ and the dye molecules show affinity to the bio-adsorbent $(\Delta S>0)$.

The MSR-DCK model was the most appropriate to represent the adsorption kinetic data for different initial concentrations (initial concentration of $300 \mathrm{mg} . \mathrm{L}^{-1}, \chi^{2}=1.4, R^{2}=0.97, \% e=3.6$ and $\%$ $D P= \pm 1.4)$ through non-linear regression. This model includes two simultaneous phenomena: a diffusion stage of the dye molecules to the active sites of the adsorbent matrix, and a surface adsorption mechanism on these active sites. The plot of $t / Q$ vs time showed a deviation from the linearity at the initial time of the process $(1 \mathrm{~h})$; this indicates the contribution of diffusion to the rate-controlling step of adsorption at short contact times.

Equilibrium was reached after $10 \mathrm{~h}$ achieving a \%RM greater than $80 \%$ for an initial concentration of $300 \mathrm{mg}$. $\mathrm{L}^{-1}$ of RR-195. The maximum adsorption capacity $\left(Q_{m}=82.1 \mathrm{mg} . \mathrm{g}^{-1}\right)$ and the $\% R M$ values ( $>80 \%$ ) after $10 \mathrm{~h}$ established that $\mathrm{CP}$ should be a potent adsorption material, being among the top three adsorbent materials for RR-195 dye removal.

FTIR-ATR, SEM-EDS and zeta potential analysis allowed establishing the type of interaction between dye molecules and the bio-sorbent; results indicated that the interactions are of an electrostatic nature with the presence of hydrogen bonding between dye and amino groups. Desorption/regeneration experiments showed that CP can be used in adsorption/desorption cycles for the treatment of wastewater containing RR-195. The information presented in this work demonstrates that coacervated chitosan particles can be an eco-friendly bioadsorbent for the remediation of industrial wastewater.

\section{Acknowledgments}

The authors gratefully acknowledge the financial support from Universidad Nacional de La Plata (UNLP), Consejo Nacional de Investigaciones Científicas y Técnicas (CONICET), Comisión de Investigaciones Científicas de la Provincia de Buenos Aires (CIC), and Agencia Nacional de Promoción Científica y Tecnológica (ANPCYT) . The collaboration of the Centro de Tecnología de Recursos Minerales y Cerámica (CETMIC) in the SEM-EDS studies is also acknowledged.

\section{Appendix A. Supplementary data}

Supplementary material related to this article can be found, in the online version, at doi:https://doi.org/10.1016/j.jece.2018.10.039.

\section{References}

[1] K. Hunger, Dyes, general survey, Industrial Dyes: Chemistry, Properties, Applications, Wiley Subscription Services, Inc. A Wiley Company, Frankfurt, 2003, pp. 1-10, https://doi.org/10.1021/ja0335418.

[2] H.K. No, S.P. Meyers, Application of chitosan for treatment of wastewaters, Rev. Environ. Contam. Toxicol. 163 (2000) 1-27.

[3] P. Kaushik, A. Malik, Fungal dye decolourization: recent advances and future potential, Environ. Int. 35 (2009) 127-141, https://doi.org/10.1016/j.envint.2008. 05.010 .

[4] A. Srinivasan, T. Viraraghavan, Decolorization of dye wastewaters by biosorbents: a review, J. Environ. Manage. 91 (2010) 1915-1929, https://doi.org/10.1016/j. jenvman.2010.05.003.

[5] S. Seshadri, P.L. Bishop, A.M. Agha, Anaerobic/aerobic treatment of selected azo 
dyes in wastewater, Waste Manag. 14 (1994) 127-137, https://doi.org/10.1016/ 0956-053X(94)90005-1.

[6] L. Fishbein, Aromatic amines and azo dyes, in: L. Fishbein (Ed.), Studies in Environmental Science, Elsevier, Amsterdam, 1979, pp. 356-416, , https://doi.org/ 10.1016/S0166-1116(08)71329-3.

[7] G. Crini, Non-conventional low-cost adsorbents for dye removal: a review, Bioresour. Technol. 97 (2006) 1061-1085, https://doi.org/10.1016/J.BIORTECH. 2005.05.001.

[8] E. Alver, A.U. Metin, Anionic dye removal from aqueous solutions using modified zeolite: adsorption kinetics and isotherm studies, Chem. Eng. J. 200 (2012) 59-67, https://doi.org/10.1016/j.cej.2012.06.038.

[9] M. Vakili, M. Rafatullah, B. Salamatinia, A.Z. Abdullah, M.H. Ibrahim, K.B. Tan, Z. Gholami, P. Amouzgar, Application of chitosan and its derivatives as adsorbents for dye removal from water and wastewater: a review, Carbohydr. Polym. 113 (2014) 115-130, https://doi.org/10.1016/j.carbpol.2014.07.007.

[10] R. Hrdina, Reactive dyes for animal fibers and synthetic polyamides, Chem. Listy 91 (1997) 149-159 http://www.chemicke-listy.cz/ojs3/index.php/chemicke-listy/ article/view/2786/2773

[11] M. Kanik, P.J. Hauser, Printing of cationised cotton with reactive dyes, Color. Technol. 118 (2002) 300-306, https://doi.org/10.1111/j.1478-4408.2002. tb00114.x.

[12] S. Farias, D. de Oliveira, A.A. Souza, S.M.A. Souza, A.F. Morgado, Removal of reactive blue 21 and reactive red 195 dyes using horseradish peroxidase as catalyst, Braz. J. Chem. Eng. 34 (2017) 701-707.

[13] K. Hunger, Dye Classes For Principal Applications, in: Industrial Dyes: Chemistry, Properties, Applications, Wiley Subscription Services, Inc., A Wiley Company, Frankfurt, 2003, pp. 113-132, https://doi.org/10.1021/ja0335418.

[14] J.F. Kouba, P. Zhuang, Color removal for textile dyeing wastewater, Fluid/Part. Sep. J. 7 (1994) 87-90.

[15] V.K. Gupta, Suhas, Application of low-cost adsorbents for dye removal - a review, J. Environ. Manage. 90 (2009) 2313-2342, https://doi.org/10.1016/j.jenvman.2008. 11.017.

[16] A. Demirbas, Agricultural based activated carbons for the removal of dyes from aqueous solutions: a review, J. Hazard. Mater. 167 (2009) 1-9, https://doi.org/10. 1016/j.jhazmat.2008.12.114

[17] M.E. Mahmoud, G.M. Nabil, N.M. El-Mallah, H.I. Bassiouny, S. Kumar, T.M. AbdelFattah, Kinetics, isotherm, and thermodynamic studies of the adsorption of reactive red 195 A dye from water by modified Switchgrass Biochar adsorbent, J. Ind. Eng. Chem. 37 (2016) 156-167, https://doi.org/10.1016/j.jiec.2016.03.020.

[18] W. Wang, G. Tian, D. Wang, Z. Zhang, Y. Kang, L. Zong, A. Wang, All-into-one strategy to synthesize mesoporous hybrid silicate microspheres from naturally rich red palygorskite clay as high-efficient adsorbents, Nat. Sci. Rep. 6 (2016), https:// doi.org/10.1038/srep39599.

[19] G. Crini, P.M. Badot, Application of chitosan, a natural aminopolysaccharide, for dye removal from aqueous solutions by adsorption processes using batch studies: a review of recent literature, Progr. Polym. Sci. (Oxford) 33 (2008) 399-447, https:// doi.org/10.1016/j.progpolymsci.2007.11.001.

[20] K.R. Ramakrishna, T. Viraraghavan, Dye removal using low cost adsorbents, Water Sci. Technol. 36 (1997) 189-196, https://doi.org/10.1016/S0273-1223(97) 00387-9.

21] V. Belessi, G. Romanos, N. Boukos, D. Lambropoulou, C. Trapalis, Removal of Reactive Red 195 from aqueous solutions by adsorption on the surface of $\mathrm{TiO}_{2}$ nanoparticles, J. Hazard. Mater. 170 (2009) 836-844, https://doi.org/10.1016/j jhazmat.2009.05.045.

[22] F. Ciçek, D. Özer, A. Özer, A. Özer, Low cost removal of reactive dyes using wheat bran, J. Hazard. Mater. 146 (2007) 408-416, https://doi.org/10.1016/j.jhazmat. 2006.12.037.

23] A.Y. Dursun, O. Tepe, Removal of Chemazol Reactive Red 195 from aqueous solution by dehydrated beet pulp carbon, J. Hazard. Mater. 194 (2011) 303-311, https://doi.org/10.1016/j.jhazmat.2011.07.105.

[24] A. Xue, S. Zhou, Y. Zhao, X. Lu, P. Han, Adsorption of reactive dyes from aqueous solution by silylated palygorskite, Appl. Clay Sci. 48 (2010) 638-640, https://doi. org/10.1016/j.clay.2010.03.011.

[25] Z. Tahir, S.R. Malik, M. Mehmood, Adsorption studies of reactive red 195 dye using modified rice husk, Sci. Int. (LAHORE). 28 (2016) 951-954.

[26] O. Aksakal, H. Ucun, Equilibrium, kinetic and thermodynamic studies of the biosorption of textile dye (Reactive Red 195) onto Pinus sylvestris L, J. Hazard. Mater. 181 (2010) 666-672, https://doi.org/10.1016/j.jhazmat.2010.05.064.

[27] S. Yi, Y. Dong, B. Li, Z. Ding, X. Huang, L. Xue, Adsorption and fixation behaviour of CI Reactive Red 195 on cotton woven fabric in a nonionic surfactant Triton X-100 reverse micelle, Color. Technol. 126 (2012) 306-314, https://doi.org/10.1111/j. 1478-4408.2012.00381.x.

[28] J. Synowiecki, N.A. Al-Khateeb, Production, Properties, and Some New Applications of Chitin and Its Derivatives, Crit. Rev. Food Sci. Nutr. 43 (2003) 145-171, https:// doi.org/10.1080/10408690390826473.

[29] J. Lizardi-Mendoza, W. Argüelles-Monal, M. Goycoolea-Valencia, Chemical characteristics and functional properties of chitosan, in: S. Bautista-Baños, G. Romanazzi, A. Jiménez-Aparicio (Eds.), Chitosan in the Preservation of Agricultural Commodities, Academic Press/Elsevier, USA, 2016, pp. 3-31, , https:// doi.org/10.1016/ B978-0-12-802735-6.00001-X.

[30] B. Meyssami, A.B. Kasaeian, Use of coagulants in treatment of olive oil wastewater model solutions by induced air flotation, Bioresour. Technol. 96 (2005) 303-307, https://doi.org/10.1016/j.biortech.2004.04.014.

[31] G. Crini, Non-conventional adsorbents for dye removal, in: S.K. Sharma (Ed.), Green Chemistry for Dyes Removal from Waste Water: REsearch Trends and Applications, John Wiley \& Sons, Beverly, U.S.A, 2015, , https://doi.org/10.1002/ 9781118721001.ch10 p. 359.

[32] Y. Wen, W. Liu, Z Fang W. Liu, Effects of adsorption interferents on removal of Reactive Red 195 dye in wastewater by chitosan, J. Environ. Sci. (China) 17 (2005) 755-769.

[33] F.C. Wu, R.L. Tseng, R.S. Juang, Comparative adsorption of metal and dye on flakeand bead-types of chitosans prepared from fishery wastes, J. Hazard. Mater. 73 (2000) 63-75, https://doi.org/10.1016/S0304-3894(99)00168-5.

[34] J. Brugnerotto, J. Lizardi, F.M. Goycoolea, W. Argüelles-Monal, J. Desbrières, M. Rinaudo, An infrared investigation in relation with chitin and chitosan characterization, Polymer 42 (2001) 3569-3580, https://doi.org/10.1016/S00323861(00)00713-8

[35] C.A. Schneider, W.S. Rasband, K.W. Eliceiri, NIH Image to ImageJ: 25 years of image analysis, Nat. Methods 9 (2012) 671-675, https://doi.org/10.1038/nmeth. 2089.

[36] M. Thommes, K. Kaneko, A.V. Neimark, J.P. Olivier, F. Rodriguez-Reinoso, J. Rouquerol, K.S.W. Sing, Physisorption of gases, with special reference to the evaluation of surface area and pore size distribution (IUPAC Technical Report), Pure Appl. Chem. 87 (2015) 1061-1069, https://doi.org/10.1515/pac-2014-1117.

[37] K. Azlan, W.N. Wan Saime, L. Lai Ken, Chitosan and chemically modified chitosan beads for acid dyes sorption, J. Environ. Sci. China (China) 21 (2009) 296-302, https://doi.org/10.1016/S1001-0742(08)62267-6.

[38] F. Rouquerol, J. Rouquerol, K.S.W. Sing, Adsorption by Powders and Porous Soldids: Principles, Methodology and Applications, 2nd ed., Academic Press, London, 2013, pp. 11-14, https://doi.org/10.1016/B978-012598920-6/50000-2.

[39] G. Crini, F. Gimbert, C. Robert, B. Martel, O. Adam, N. Morin-Crini, F. De Giorgi, P.M. Badot, The removal of Basic Blue 3 from aqueous solutions by chitosan-based adsorbent: Batch studies, J. Hazard. Mater. 153 (2008) 96-106, https://doi.org/10. 1016/j.jhazmat.2007.08.025.

[40] K.B. Tan, M. Vakili, B.A. Horri, P.E. Poh, A.Z. Abdullah, B. Salamatinia, Adsorption of dyes by nanomaterials: recent developments and adsorption mechanisms, Sep. Purif. Technol. 150 (2015) 229-242, https://doi.org/10.1016/j.seppur.2015.07. 009

[41] X. Liu, L. Zhang, Removal of phosphate anions using the modified chitosan beads: adsorption kinetic, isotherm and mechanism studies, Powder Technol. 277 (2015) 112-119, https://doi.org/10.1016/j.powtec.2015.02.055.

[42] V.N. Tirtom, A. Dinçer, S. Becerik, T. Aydemir, A. Çelik, Comparative adsorption of $\mathrm{Ni}(\mathrm{II})$ and $\mathrm{Cd}(\mathrm{II})$ ions on epichlorohydrin crosslinked chitosan-clay composite beads in aqueous solution, Chem. Eng. J. 197 (2012) 379-386, https://doi.org/10.1016/ J.CEJ.2012.05.059.

[43] W.Y. Li, J. Liu, H. Chen, Y. Deng, B. Zhang, Z. Wang, X. Zhang, S. Hong, Application of oxalic acid cross-linking activated alumina/chitosan biocomposites in defluoridation from aqueous solution. Investigation of adsorption mechanism, Chem. Eng. J. 225 (2013) 865-872, https://doi.org/10.1016/J.CEJ.2013.03.105.

[44] T.Y. Kim, S.S. Park, S.Y. Cho, Adsorption characteristics of Reactive Black 5 onto chitosan beads cross-linked with epichlorohydrin, J. Ind. Eng. Chem. 18 (2012) 1458-1464, https://doi.org/10.1016/j.jiec.2012.02.006.

[45] G.Z. Kyzas, D.N. Bikiaris, N.K. Lazaridis, Low-swelling chitosan derivatives as biosorbents, Langmuir 24 (2008) 4791-4799, https://doi.org/10.1021/la7039064.

[46] L. Çelik, A. Öztürk, M.I. Abdullah, Biodegradation of reactive red 195 azo dye by the bacterium Rhodopseudomonas palustris 51ATA, Afr. J. Microbiol. Res. 6 (2012) 120-126, https://doi.org/10.5897/AJMR11.1059.

[47] G.S. Ghodake, A.A. Talke, J.P. Jadhav, S.P. Govindwar, Potential of Brassica juncea in order to treat textile-effluent- contaminated sites, Int. J. Phytoremediation 11 (2009) 297-312, https://doi.org/10.1080/15226510802429518.

[48] K. Takayama, M. Hirata, Y. Machida, T. Masada, T. Sannan, T. Nagai, Effect of interpolymer complex formation on bioadhesive property and drug release phenomenon of compressed tablet consisting of chitosan and sodium hyaluronate, Chem. Pharm. Bull. 38 (1990) 1993-1997, https://doi.org/10.1248/cpb.38.1993.

[49] O. Liu, B. Yang, L. Zhang, R. Huang, Adsorption of an anionic azo dye by crosslinked chitosan/bentonite composite, Int. J. Bio. Macro. 72 (2015) 1129-1135, https://doi.org/10.1016/j.ijbiomac.2014.10.008.

[50] I. Langmuir, The constitution and fundamental properties of solids and liquids, J. Am. Chem. Soc. 38 (1917) 2221-2295, https://doi.org/10.1021/ja02254a006.

[51] H.M.F. Freundlich, Over the adsorption in solution, J. Phys. Chem. 57 (1906) 387-471, https://doi.org/10.1016/j.jclepro.2017.04.078.

[52] G. Mckay, H.S. Blair, J.R. Gardner, Adsorption of dyes on chitin. I. Equilibrium studies, J. Appl. Polym. Sci. 27 (1982) 3043-3057, https://doi.org/10.1002/app 1982.070270827.

[53] E.R. García, R.L. Medina, M.M. Lozano, I. Hernández Pérez, M.J. Valero, A.M.M. Franco, Adsorption of azo-dye orange II from aqueous solutions using a metal-organic framework material: iron-benzenetricarboxylate, Materials 7 (2014) 8037-8057, https://doi.org/10.3390/ma7128037.

[54] M.J. Temkin, V. Pyzhev, Kinetics of ammonia synthesis on promoted iron catalysts, Acta Physicochim URSS 12 (1940) 217-222.

[55] M. Dubinin, L. Radushkevich, The equation of the characteristic curve of activated charcoal, Proc. Acad. Sci. Phys. Chem. Sect. 55 (1947) 327-329, https://doi.org/10 4236/ojs.2014.41001.

[56] O. Redlich, D.L. Peterson, A useful adsorption isotherm, J. Phys. Chem. 63 (1959) 1024, https://doi.org/10.1021/j150576a611.

[57] R. Saini, C.V. Raghunath, P. Pandey, P. Kumar, Optimization of Fenton oxidation for the removal of methyl parathion in aqueous solution, Perspect. Sci. 8 (2016) 670-672, https://doi.org/10.1016/j.pisc.2016.06.054.

[58] K.V. Kumar, Comparative analysis of linear and non-linear method of estimating the sorption isotherm parameters for malachite green onto activated carbon, J. Hazard. Mater. 136 (2006) 197-202, https://doi.org/10.1016/J.JHAZMAT.2005.09.018.

[59] Y.C. Wong, Y.S. Szeto, W.H. Cheung, G. McKay, Adsorption of acid dyes on chitosan 
- equilibrium isotherm analyses, Process Biochem. 39 (2004) 693-702, https://doi. org/10.1016/S0032-9592(03)00152-3.

[60] G.L. Dotto, J.M. Moura, T.R.S. Cadaval, L.A.A. Pinto, Application of chitosan films for the removal of food dyes from aqueous solutions by adsorption, Chem. Eng. J. (2013), https://doi.org/10.1016/j.cej.2012.10.027.

[61] R.-S. Juang, R.-L. Tseng, F.-C. Wu, S.-H. Lee, Adsorption behavior of reactive dyes from aqueous solutions on chitosan, J. Chem. Tech. Biotechnol. 70 (1997) 391-399, https://doi.org/10.1002/(SICI)1097-4660(199712)70:4<391::AID-JCTB792>3.0. $\mathrm{CO} \cdot 2$.

[62] L. Zhang, Z. Cheng, X. Guo, X. Jiang, R. Liu, Process optimization, kinetics and equilibrium of orange $\mathrm{G}$ and acid orange 7 adsorptions onto chitosan/surfactant, J. Mol. Liq. 197 (2014) 353-367, https://doi.org/10.1016/J.MOLLIQ.2014.06.007.

[63] G.Z. Kyzas, N.K. Lazaridis, M. Kostoglou, Adsorption/desorption of a dye by a chitosan derivative: experiments and phenomenological modeling, Chem. Eng. J. 248 (2014) 327-336, https://doi.org/10.1016/j.cej.2014.03.063.

[64] H.N. Tran, S.-J. You, A. Hosseini-Bandegharaei, H.-P. Chao, Mistakes and inconsistencies regarding adsorption of contaminants from aqueous solutions: a critical review, Water Res. 120 (2017) 88-116, https://doi.org/10.1016/j.watres.2017.04. 014.

[65] Y. Liu, Is the free energy change of adsorption correctly calculated? J. Chem. Eng. Data 54 (2009) 1981-1985, https://doi.org/10.1021/je800661q.

[66] X. Wang, C. Chen, Nanotechnology application in metal ion adsorption, in: L.K. Wang, J.P. Chen, Y.T. Hung, N.K. Shammas (Eds.), Heavy Metals in the Environment, CRC Press, Boca Raton, FL, 2009p. 166.

[67] A.K. Jain, V.K. Gupta, S. Jain, Suhas, Removal of chlorophenols using industrial wastes, Environ. Sci. Technol. 38 (2004) 1195-1200, https://doi.org/10.1021/ es034412u.
[68] Y. Liu, X. Liu, W. Dong, L. Zhang, Q. Kong, W. Wang, Efficient adsorption of sulfamethazine onto modified activated carbon: a plausible adsorption mechanism, Nat. Sci. Rep. 7 (2017) 1-12, https://doi.org/10.1038/s41598-017-12805-6.

[69] J.F. Corbett, Pseudo first-order kinetics, Int. J. Chem. Educ. Res. 49 (1972) 663, https://doi.org/10.1021/ed049p663.

[70] Y.S. Ho, G. McKay, Pseudo-second order model for sorption processes, Process Biochem. 34 (1999) 451-465, https://doi.org/10.1016/S0032-9592(98)00112-5.

[71] F.C. Wu, R.L. Tseng, R.S. Juang, Characteristics of Elovich equation used for the analysis of adsorption kinetics in dye-chitosan systems, Chem. Eng. J. 150 (2009) 366-373, https://doi.org/10.1016/j.cej.2009.01.014.

[72] W.J. Weber, J.C. Morris, Kinetics of adsorption on carbon from solution, J. Sanit. Eng. Div. 89 (1963) 31-60.

[73] W.H. Cheung, Y.S. Szeto, G. McKay, Intraparticle diffusion processes during acid dye adsorption onto chitosan, Bioresour. Technol. 98 (2007) 2897-2904, https:// doi.org/10.1016/j.biortech.2006.09.045.

[74] M. Haerifar, S. Azizian, Mixed surface reaction and diffusion-controlled kinetic model for adsorption at the solid/solution interface, J. Phy. Chem. C. 117 (2013) 8310-8317, https://doi.org/10.1021/jp401571m.

[75] S. Chatterjee, S. Chatterjee, B.P. Chatterjee, A.R. Das, A.K. Guha, Adsorption of a model anionic dye, eosin Y, from aqueous solution by chitosan hydrobeads, J. Colloid Interface Sci. 288 (2005) 30-35, https://doi.org/10.1016/J.JCIS.2005.02. 055.

[76] E. Guibal, Interactions of metal ions with chitosan-based sorbents: a review, Sep Purif. Technol. 38 (2004) 43-74, https://doi.org/10.1016/j.seppur.2003.10.004.

[77] C.Y. Chen, J.C. Chang, A.H. Chen, Competitive biosorption of azo dyes from aqueous solution on the templated crosslinked-chitosan nanoparticles, J. Hazard. Mater. 185 (2011) 430-441, https://doi.org/10.1016/j.jhazmat.2010.09.051. 